\title{
Nuclear speckle specific hnRNP D-like prevents age- and AD-related cognitive decline by modulating RNA splicing
}

Qingyang Zhang ${ }^{1}$, Juan Zhang ${ }^{1,2}$, Jin Ye ${ }^{3}$, Xiaohui Li ${ }^{1,2}$, Hongda Liu', Xiaolin Ma ${ }^{1}$, Chao Wang ${ }^{3}$, Keqiang He ${ }^{4}$, Wei Zhang ${ }^{4}$, Ji Yuan ${ }^{4}$, Yingjun Zhao ${ }^{5}$, Huaxi $X u^{5^{*}}$ and Qiang Liu ${ }^{1,2,6^{*}}$ (D)

\begin{abstract}
Background: Aberrant alternative splicing plays critical role in aging and age-related diseases. Heterogeneous nuclear ribonucleoproteins (hnRNPs) reportedly regulate RNA splicing process. Whether and how hnRNPs contribute to age-related neurodegenerative diseases, especially Alzheimer's disease (AD), remain elusive.

Methods: Immunoblotting and immunostaining were performed to determine expression patterns and cellular/ subcellular localization of the long isoform of hnRNP D-like (L-DL), which is a hnRNP family member, in mouse hippocampus. Downregulation of L-DL in WT mice was achieved by AAV-mediated shRNA delivery, followed by memory-related behavioural tests. L-DL interactome was analysed by affinity-precipitation and mass spectrometry. Alternative RNA splicing was measured by RNA-seq and analyzed by bioinformatics-based approaches. Downregulation and upregulation of L-DL in APP/PS1 mice were performed using AAV-mediated transduction.

Results: We show that L-DL is specifically localized to nuclear speckles. L-DL levels are decreased in the hippocampus of aged mouse brains and downregulation of L-DL impairs cognition in mice. L-DL serves as a structural component to recruit other speckle proteins, and regulates cytoskeleton- and synapse-related gene expression by altering RNA splicing. Mechanistically, these splicing changes are modulated via L-DL-mediated interaction of SF3B3, a core component of U2 snRNP, and U2AF65, a U2 spliceosome protein that guides U2 snRNP's binding to RNA. In addition, L-DL levels are decreased in APP/PS1 mouse brains. While downregulation of L-DL deteriorates memory deficits and overexpression of L-DL improves cognitive function in AD mice, by regulating the alternative splicing and expression of synaptic gene CAMKV.
\end{abstract}

Conclusions: Our findings define a molecular mechanism by which hnRNP L-DL regulates alternative RNA splicing, and establish a direct role for L-DL in AD-related synaptic dysfunction and memory decline.

Keywords: hnRNP DL, Aging, Alzheimer's disease (AD), Cognition, Nuclear speckles, Alternative splicing

\footnotetext{
* Correspondence: hxxu@xmu.edu.cn; liuq2012@ustc.edu.cn

${ }^{5}$ The First Affiliated Hospital of Xiamen University, Fujian Provincial Key

Laboratory of Neurodegenerative Disease and Aging Research, Institute of Neuroscience, Xiamen University, Xiamen 361000, China

'Institute on Aging and Brain Disorders, The First Affiliated Hospital of USTC, Hefei National Laboratory for Physical Sciences at the Microscale, Division of Life Sciences and Medicine, University of Science and Technology of China, Hefei 230026, China

Full list of author information is available at the end of the article
}

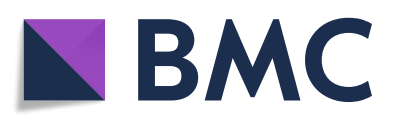

(c) The Author(s). 2021 Open Access This article is licensed under a Creative Commons Attribution 4.0 International License, which permits use, sharing, adaptation, distribution and reproduction in any medium or format, as long as you give appropriate credit to the original author(s) and the source, provide a link to the Creative Commons licence, and indicate if changes were made. The images or other third party material in this article are included in the article's Creative Commons licence, unless indicated otherwise in a credit line to the material. If material is not included in the article's Creative Commons licence and your intended use is not permitted by statutory regulation or exceeds the permitted use, you will need to obtain permission directly from the copyright holder. To view a copy of this licence, visit http://creativecommons.org/licenses/by/4.0/. The Creative Commons Public Domain Dedication waiver (http://creativecommons.org/publicdomain/zero/1.0/) applies to the data made available in this article, unless otherwise stated in a credit line to the data. 


\section{Background}

Alternative splicing is a process wherein specific regulators modulate core splicing machinery to selectively generate various splicing variants [1]. Pre-mRNA splicing relies on recruitment of a large ribonucleoprotein complex, known as spliceosome, at $5^{\prime}$ and $3^{\prime}$ splice sites (5' SS and 3'SS). Typically, the 3'SS is bound by U2 auxiliary factors (U2AFs) in spliceosome assembly, wherein U2AF small subunit U2AF35 binds to the 3' SS, and the large subunit U2AF65 binds to the polypyrimidine tract adjacent to the 3' SS [2]. U2AF65 interacts with core U2 small nuclear ribonucleoprotein (U2 snRNP) component splicing factor 3B (SF3B), such as SF3B1, SF3B2 or SF3B3, to promote binding of U2 snRNP to branch sites and subsequent splicing complex formation and activation, eventually intron removal [3].

Brain aging is an irreversible physiological process, accompanied by decreased cognitive function and memory loss [4]. Aging is a major risk factor for the progression of neurodegenerative diseases [5, 6]. Mounting evidence has shown a global change in alternative splicing during brain aging and age-related neurodegenerative diseases [7]. Moreover, aberrant splicing produces irregular splicing products with defective or even harmful functions, and contributes to aging or age-related diseases [8]. For instance, exon 18 skipping of postsynaptic density protein 95 (PSD95) results in generation of a splicing variant with premature translational termination, and this splicing variant is prone to degradation through nonsense-mediated decay (NMD) pathway, resulting in reduced levels of PSD95 [9]. This splicing change of PSD95 is promoted by polypyrimidine tract binding protein 1 (PTBP1), whose levels are significantly increased upon aging progression [10]. These findings suggest that age-dependent RNA binding protein-mediated alternative splicing is responsible for alterations in synaptic structure and function during aging progression. BACE1, which encodes $\beta$-secretase 1 that catalyzes amyloid precursor protein into $\beta$-amyloid $(A \beta)$, undergoes extensive alternative splicing upon aging $[11,12]$. As a result, fulllength BACE1 shows an age-dependent increase, resulting in a rise in BACE1 level and a consequent accumulation of $A \beta$ in the brain [13]. This leads to age-related cognitive impairment and AD progression [14-16]. Notably, a mutation in intron 4 of presenilin 1 (PS1) leads to production of an aberrant transcript and a full-length PS1 with insertion of an extra threonine, consequently promoting $\mathrm{A} \beta 42$ production and $\mathrm{AD}$ pathology $[17,18]$.

Nuclear speckles, also known as SC35 domain, are originally discovered as a storage site for RNA processing factors with functions predominantly linked to the alternative splicing of pre-mRNA [19]. The shape and size of nuclear speckles are in a dynamic change due to continual exchange of splicing factors between speckles and nucleoplasm [20]. Cellular processes such as Pol II transcription and splicing are involved in dynamic changes of nuclear speckles [21]. Heterogeneous nuclear ribonucleoproteins (hnRNPs), a classic splicing regulator, are extensively involved in alternative splicing regulation [1]. Biochemical purification and proteomic analyses have identified the existence of multiple hnRNPs in nuclear speckles, which may contribute to maintaining the structural and functional integrity of nuclear speckles [22, 23].

Here, we demonstrate that L-DL is predominantly expressed in neurons and its levels are significantly decreased in the hippocampus of both aged and AD brains. Particularly, deficiency of L-DL in the hippocampus impairs cognitive function. We uncover that L-DL is specifically localized to nuclear speckles, serving as a structural component to maintain the structure of this nuclear body. Moreover, L-DL regulates splicing patterns of multiple cytoskeleton- and synapse-related genes via modulating the loading of U2 snRNP-mediated spliceosome on their pre-mRNAs. In addition, L-DL levels are reduced in APP/PS1 (AD model) mouse brains, and further downregulation of L-DL in these mice deteriorates memory decline, whereas overexpression of L-DL restores synaptic protein expressions and cognitive function in AD mice. Taken together, these findings suggest that nuclear speckle specific L-DL regulates aging- and AD-related cognitive function via modulating alternative splicing of cytoskeleton- and synapse-related genes.

\section{Methods}

\section{Cell culture and plasmid transfection}

Neuro-2a cells (N2a) (ATCC, CCL-131) and 293T cells (ATCC, CRL-3216) were cultured according to standard procedures. Cells were growing in DMEM (Gibco, \#12100061) supplemented with 10\% FBS (Biological Industries, \#1827594) and $1 \%$ penicillin/streptomycin (Gibco, \#15070063) and incubated in 5\% humidified $\mathrm{CO}_{2}$ incubator at $37^{\circ} \mathrm{C}$. Plasmid transfection was performed when cells were approximately $70-80 \%$ confluent using PEI (Sigma-Aldrich, \#408727).

\section{Animals}

C57BL/6 J mice were purchased from GemPharmatech and APP/PS1 mice were purchased from Shanghai Model Organisms Center. All experimental protocols were approved by the Animal Studies Committee at University of Science and Technology, Hefei, China.

\section{Plasmid construction}

To generate pcDNA 3.1 (+)-GST vector, GST sequence was PCR amplified from pcDNA3.1 + N-GST (TEV) (GenScript) and subcloned into Nhe I / EcoR I 
restriction sites of pcDNA $3.1(+)$ (Thermo Fisher Scientific, \#V790-20). To generate pcDNA 3.1 (+)-GST-L-DL plasmid, the coding sequence of L-DL was PCR amplified from cDNA derived from mouse hippocampus, then subcloned into EcoR I / Xho I restriction sites of pcDNA 3.1 (+)-GST vector. Primers for cloning are listed in Table S1.

Splicing reporter was constructed according to previously published [24]. Luciferase-intron-Mutant (luciferase-Mut), which was generated by inserting an immunoglobulin intron (Promega, \#U47119) into firefly luciferase gene, and wild-type firefly luciferase (luciferase-WT) with PEST and CL1 sequence for protein destabilization were synthesized (Tsingke) and subcloned into BamH I / EcoR I restriction sites of pcDNA 3.1 (+) vector.

For adeno-associated virus (AAV) plasmid expressing L-DL shRNA, four H1 promoter driven L-DL shRNA sequences were tandemly arranged and synthesized (Tsingke), then subcloned into BamH I / EcoR I restriction sites of pAAV-EF1a-DIO-Gcamp6s vectors (Addgene, \#67526), wherein EF1a promoter was substituted with CamkIl $\alpha$ promoter followed by zsGreen sequence for neuron-specific visualization of the injected areas. AAV was produced and microinjected into the hippocampus of mouse brains for knockdown. The sequences of luciferase-WT, luciferase-Mut and four tandemly arranged L-DL shRNA sequences are listed in Table S2.

L-DL sgRNAs were designed using online sgRNA designing tools: https://sg.idtdna.com/site/order/ designtool/index/CRISPR_SEQUENCE. Four mouse sgRNAs and four human sgRNAs were separately subcloned into the BsmB I site of LentiCRISPR v2 plasmid (Addgene, \#52961) as previously described [25, 26]. These sgRNA sequences are listed in Table S3.

\section{CRISPR-Cas9 mediated L-DL knockout in cells}

Mixture of four L-DL-sgRNA on lentiCRISPR plasmid were co-transfected into $293 \mathrm{~T}$ cells, together with packaging plasmid (pHR'8.2deltaR) and envelope plasmid (pCMV-VSV-G). Virus-containing medium was harvested $48 \mathrm{~h}$ after the transfection. Cells were treated with virus containing medium for $48 \mathrm{~h}$. Transduced cells were selected with $10 \mu \mathrm{g} / \mathrm{ml}$ of puromycin.

\section{Protein extraction and Western blot}

Cells and brain tissues were lysed in PBS plus 1\% Trion $\mathrm{X}-100$ and $1 \%$ protease inhibitor cocktail (Targetmol, \#C0001), following by sonication. Protein concentration was measured with BCA Protein Assay Kit (Thermo Fisher Scientific, \#23250) and equal amount of protein was separated by SDS-PAGE electrophoresis. Proteins were then transferred from gel to $0.45 \mu \mathrm{m}$ nitrocellulose membrane (Pall Corporation, \#27182369). Membranes were blocked with 5\% non-fat milk in Tris buffered saline containing $0.1 \%$ Tween 20 (TBST) for $1 \mathrm{~h}$, following by incubation with primary antibodies at $4{ }^{\circ} \mathrm{C}$ overnight. The following primary antibodies were used: rabbit anti-L-DL (Sigma-Aldrich, \#HPA063147) at dilution of 1:2,000, rabbit anti-hnRNP DL (Abcepta, \#AP5352c) at dilution of 1:1,000, mouse anti-GST (Santa Cruz Biotechnology, \#sc-138) at dilution of 1:5,000, mouse anti-RBM25 (Santa Cruz Biotechnology, \#sc374271) at dilution of 1:500, mouse anti-NPM1 (Proteintech, \#60096-1-Ig) at dilution of 1:2,000, mouse antiPML (Abcam, \#ab6263) at dilution of 1:1,000, mouse anti-SF3B1 (Santa Cruz Biotechnology, \#sc-514655) at dilution of 1:1,000 dilution, mouse anti-U2AF65 (Santa Cruz Biotechnology, \#sc-53942) at dilution of 1:1,000, mouse anti-U2AF35 (Proteintech, \#60289-1-Ig) at dilution of 1:2,500, rabbit anti-SF3B3 (Proteintech, \#145771-AP) at dilution of 1:2,000, rabbit anti-PSD95 (Proteintech, \#20665-1-AP) at dilution of1:1,000, rabbit antiSNAP25 (Proteintech, \#14903--1-AP) at dilution of 1: 5,000, rabbit anti-CAMKV (Proteintech, \#14788-1-AP) at dilution of 1:1,000, rabbit anti-NR2B (Proteintech, \#21920-1-AP) at dilution of 1:2,000, rabbit anti-SC35 (Abclonal, \#A3635) at dilution of 1:1,000000 dilution, mouse anti-Lamin B1 (Proteintech, \#66095-1-Ig) at dilution of 1:5,000, mouse anti-GAPDH (Proteintech, \#60004-1-Ig) at dilution of 1:5,000 , rabbit anti-Lamin A/C (Proteintech, \#10298-1-AP) at dilution of 1:5,000 . Goat anti-mouse IgG $(\mathrm{H}+\mathrm{L})$ (peroxidase/HRP conjugated) (Elabscience, \#E-AB-1001) or goat anti-rabbit IgG $(\mathrm{H}+\mathrm{L})$ (peroxidase/HRP conjugated) (Elabscience, \# EAB-1003) secondary antibodies were used at dilution of 1:5,000. The immunoreactive bands were detected by Pierce ECL Western Blotting Substrate (Thermo Fisher Scientific, \#32209). For densitometric analyses, immunoreactive bands were quantified using Fiji software (https://imagej.nih.gov/ij/).

\section{Immunofluorescence staining}

Cells seeded on cover slips were washed 3 times with PBS, following by fixation in 4\% PFA for $20 \mathrm{~min}$. Cells were permeabilized with PBS containing $0.4 \%$ Triton X100 (PBST), following by blocking with 2\% BSA in PBST for $30 \mathrm{~min}$. After blocking, cells were incubated with rabbit anti-L-DL (Sigma-Aldrich, \#HPA063147) at dilution of 1:200, mouse anti-SC35 (BD Bioscience, \#556363) at dilution of a 1:200, mouse anti-SON (Santa Cruz Biotechnology, \#sc-398508) at dilution of 1:200, mouse anti-RBM25 (Santa Cruz Biotechnology, \#sc374271) at dilution of 1:50, mouse anti-NPM1 (Proteintech, \#60096-1-Ig) at dilution of 1:200, mouse anti-PML (Abcam, \#ab6263) at dilution of 1:50, mouse anti-SMN (Abcam, \#ab5831) at dilution of 1:50 overnight at $4{ }^{\circ} \mathrm{C}$, followed by incubation with Alexa Fluor 594-conjugated Goat anti-rabbit secondary antibody (Thermo Fisher 
Scientific, \#R37117), or Alexa Fluor 488-conjugated Goat anti-mouse secondary antibody (Thermo Fisher Scientific, \#R37120), and 4', 6-diamidino-2-phenylindole dihydrochloride (DAPI) (Sigma-Aldrich, \#D9542).

Immunostaining for brain tissues was performed as described previously, with modifications [27]. Mice were anesthetized and sacrificed, then perfused with $0.9 \%$ $\mathrm{NaCl}$ solution. Brains were isolated, immersed in $4 \%$ paraformaldehyde (PFA) and cryo-preserved in 30\% sucrose for $24 \mathrm{~h}$ at $4{ }^{\circ} \mathrm{C}$. Tissues were then embedded in OCT compound and sectioned with microtome at $10 \mu \mathrm{m}$ thickness (Leica, CM1860). Glass slide-mounted sections were washed with TBS $(20 \mathrm{mM}$ Tris, $150 \mathrm{mM}$ $\mathrm{NaCl}, \mathrm{pH}$ 7.2), permeabilized with TBS containing $0.25 \%$ Triton X-100, followed by blocking with $0.5 \%$ BSA in TBST buffer $(20 \mathrm{mM}$ Tris, $150 \mathrm{mM} \mathrm{NaCl}, 0.1 \%$ Triton $\mathrm{X}-100, \mathrm{pH} 7.2)$ for $1 \mathrm{~h}$. Sections were then incubated with rabbit anti-L-DL (Sigma-Aldrich) at dilution of a 1: 400, mouse anti-GFAP (BD Bioscience, \#556328) at dilution of 1:100, mouse anti-NeuN (Millipore, \#MAB377) at dilution of $1: 100$ at $4{ }^{\circ} \mathrm{C}$ overnight. After washing, slices were incubated with Alexa Fluor 594-conjugated Goat anti-rabbit secondary antibody (Thermo Fisher Scientific) or Alexa Fluor 488-conjugated Goat anti-mouse secondary antibody (Thermo Fisher Scientific). Fluorescence signals were captured with a Leica TCSSPE confocal Microscope and analysed with Fiji software.

\section{GST-L-DL co-affinity precipitation (co-AP)}

293T cells were transfected with GST-control (GSTCTRL) or GST-L-DL plasmids and cell lysates were collected with GST-binding buffer (PBS buffer with $0.1 \mathrm{mM}$ EDTA, $0.1 \%$ Triton $\mathrm{X}-100$ and $1 \%$ proteinase inhibitor cocktails, $\mathrm{pH}$ 7.4). Cells then were sonicated until the lysate was clear and transparent. Protein concentration was measured with BCA Protein Assay Kit (Thermo Fisher Scientific, \#23225) and $500 \mu \mathrm{g}$ of cell lysates were used to incubate with $30 \mu \mathrm{l}$ GST agarose beads (Cytiva, \#17075601) overnight at $4{ }^{\circ} \mathrm{C}$. Beads were washed 3 times with buffer A (PBS buffer with 0.1\% SDS and 0.3\% deoxycholate and $0.3 \%$ NP-40, pH 7.4) and buffer B (50 $\mathrm{mM}$ Tris- $\mathrm{HCl}$ with $10 \mathrm{mM} \mathrm{MgCl} 2$ and $0.5 \% \mathrm{NP}-40, \mathrm{pH}$ 7.4). GST-binding proteins were eluted with protein loading buffer $(10 \mathrm{mM}$ Tris- $\mathrm{HCl}$ with $0.4 \%$ SDS and 20 $\mathrm{mM}$ DTT and $2 \%$ glycerol and $0.05 \%$ bromophenol blue dye, $\mathrm{pH}$ 6.8). Beads were removed by centrifugation at $5,000 \mathrm{rpm}$ for $1 \mathrm{~min}$. The supernatant was collected for western blot or silver staining assay.

\section{Silver staining and Mass Spectrometry}

Silver staining was performed as described previously [28]. Briefly, gels were submerged in fixative solution (50\% ethanol, $12 \%$ acetic acid and $0.05 \%$ formalin) for 2 h, followed by washing with $20 \% \mathrm{EtOH}$ twice for $40 \mathrm{~min}$.
$0.02 \%$ sodium thiosulfate solution was used to sensitize the gel for $2 \mathrm{~min}$, followed by wash with deionized water. Gels were then incubated with $0.2 \% \mathrm{AgNO}_{3}$ containing $0.076 \%$ formalin for $20 \mathrm{~min}$, followed by wash with deionized water twice. Finally, gels were developed in $6 \%$ $\mathrm{Na}_{2} \mathrm{CO}_{3}$ solution containing $0.0004 \% \quad \mathrm{Na}_{2} \mathrm{~S}_{2} \mathrm{O}_{3}$ and $0.05 \%$ formalin for $2-5 \mathrm{~min}$ and developing was terminated in $12 \%$ acetic acids. Target bands were subjected to Mass Spectrometry (MS) analysis (PTM Biolab). Proteins identified from MS are listed on Table S4. Functional annotations were performed on website: http:// metascape.org/, with protein accession as previously described [29]. Cellular component enrichment analysis was conducted by a tool available on website: http:// geneontology.org/. Analyses on L-DL-associated protein interactions were carried out on STRING database (https://string-db.org/) (v.11.0, H. sapiens dataset, PPI enrichment $P$-value: $<1.0 \mathrm{e}-16)$ according to previously published [30].

\section{Splicing reporter assay}

Splicing reporter assay was conducted according to procedures previously described [24]. Briefly, L-DL KO and control (CTRL) N2a cells were transfected with luciferase-WT or luciferase-Mut for $12 \mathrm{~h}$. The relative luciferase activity was calculated based on the following formula:

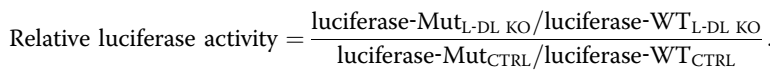

\section{RNA extraction, reverse transcription and PCR for splicing analysis}

Total RNA was extracted from cells or tissues using TRIzol Reagent (Invitrogen, \#15596026), according to manufacturer's protocol. RNA was reverse transcribed into cDNA using HiScriptIII 1st Strand cDNA Synthesis Kit (Vazyme, \#R312). For splicing analysis, specific primers were used to amplify gene splicing isoforms using Easy Taq DNA Polymerase (Transgen, \#AP111). The PCR products were analysed by $3 \%$ agarose TBE gel. The qualification of PCR products was conducted by Fiji software. Specific splicing primers are listed in Table S5.

\section{Next generation sequencing and alternative splicing analysis}

For RNA-Sequencing (RNA-Seq), total RNA was isolated from cells and mRNA was enriched by Oligo (dT) beads, followed by fragmentation and reverse transcription with random primers. Obtained cDNAs were purified, their $5^{\prime}$ and $3^{\prime}$ ends were repaired and ligated with adapters. Ligated cDNAs were amplified by PCR and subjected to Illumina Novaseq system for $150 \mathrm{nt}$ pairend sequencing (Annoroad). Reads were aligned to the 
mouse genome (Mus_musculus.GRCm38.90.chr). For alternative splicing analysis, "percent spliced in" (PSI) values, computed via rMATS (v4.1.0) software, were used to define alternative splicing levels of exon skipping, intron retention, mutually exclusive exon inclusions, alternative $5^{\prime}$ splice sites, and alternative 3 ' splice sites as previously reported [31]. The positive change of $\triangle \mathrm{PSI}\left(\mathrm{PSI}_{\mathrm{L}-\mathrm{DL}} \mathrm{KD}^{-}-\mathrm{PSI}_{\mathrm{CTRL}}>0\right)$ represents increase of inclusion and negative change $\triangle \mathrm{PSI}\left(\mathrm{PSI}_{\mathrm{L}-\mathrm{DL}} \mathrm{KD}^{-} \mathrm{PSI}_{\mathrm{CTRL}}<\right.$ 0 ) represents decrease of inclusion.

\section{Generation of adeno-associated virus and hippocampal injection}

Adeno-associated virus (AAV) was produced according to procedures previously reported [32, 33]. In Brief, AAV plasmid with target sequences, pHelper and helper 2/9 plasmid were co-transfected into $293 \mathrm{~T}$ cells in a ratio of 2:1:1 by PEI. Twenty-four hours after transfection, medium was changed to DMEM plus 2\% FBS. Both cells and medium were collected for AAV purification $72 \mathrm{~h}$ after transfection.

AAV particles were released from cells with freeze/ thaw cycles, followed by treatment with $50 \mathrm{U} / \mathrm{ml}$ benzonase nuclease (MKbio) and $10 \mathrm{U} / \mathrm{ml}$ RNase I (Vazyme) at $37^{\circ} \mathrm{C}$ for $30 \mathrm{~min}$, and incubation for another $30 \mathrm{~min}$ upon adding of $0.5 \%$ sodium deoxycholate (Sigma-Aldrich). Cell debris were removed by centrifugation at 2,500 g for $30 \mathrm{~min}, 40 \%$ PEG8000 and $2.5 \mathrm{M} \mathrm{NaCl}$ were added to precipitate the virus. The viral pellet was resuspended in PBS, and contaminated proteins were removed by chloroform and $\left(\mathrm{NH}_{4}\right)_{2} \mathrm{SO}_{4}$ extraction. Viral titter was determined by qPCR-based approach.

Male wild-type C57BL/6 J mice at 8 weeks of age were stereotaxically injected with L-DL shRNA $(0.8 \mu \mathrm{l}, 2 \times$ $\left.10^{11} \mathrm{TU} / \mathrm{ml}\right)$ or control shRNA $\left(0.8 \mu \mathrm{l}, 8 \times 10^{11} \mathrm{TU} / \mathrm{ml}\right)$ adenovirus into the bilateral CA1 areas of hippocampus with an air pressure injector system (KDS). Male APP/ PS1 mice at 6 months of age were stereotaxically injected with L-DL shRNA $\left(0.8 \mu \mathrm{l}, 2 \times 10^{11} \mathrm{TU} / \mathrm{ml}\right)$ or control shRNA $\left(0.8 \mu \mathrm{l}, 8 \times 10^{11} \mathrm{TU} / \mathrm{ml}\right)$ adenovirus, with L-DL overexpression $\left(0.5 \mu \mathrm{l}, 7 \times 10^{11} \mathrm{TU} / \mathrm{ml}\right)$ or control adenovirus $\left(0.5 \mu \mathrm{l}, 8 \times 10^{11} \mathrm{TU} / \mathrm{ml}\right)$ into the bilateral CA1 areas of hippocampus with an air pressure injector system (KDS). The coordinates used for stereotaxic injections were AP -2.3, ML 2.0, DV -1.5 and AP -2.3, ML -2.0 , DV --1.5 . Behavioural tests were conducted 4 weeks after the injection.

\section{Behavioural assays}

\section{The Morris water maze}

To evaluate spatial learning and memory, the Morris water maze task was performed according to previously published [34]. Briefly, a platform $(10 \mathrm{~cm})$ was submerged in a black circular pool (diameter: $120 \mathrm{~cm}$ ).
During the training phase, each individual mouse received consecutive trials for continuous 5 days. On probe trial day, the platform was removed and mice were allowed to swim for $90 \mathrm{~s}$ starting from site opposite to where the platform was located. Behavioural parameters were recorded by a video camera set on top of the circular pool and data were analyzed using Ethovision XT 11 software (Noldus).

\section{Novel object recognition (NOR)}

The Novel object recognition task was performed as described previously, with modifications [35, 36]. Briefly, all mice were placed in an open field box, and allowed to freely explore the empty open field arena for $5 \mathrm{~min}$ on day 1 . On day 2, each mouse was subjected to familiarization phase with exploration of two identical objects $(\mathrm{A}+\mathrm{A})$ for $5 \mathrm{~min}$. $4 \mathrm{~h}$ after the familiarization phase, mouse was allowed to explore the field with a familiar object (A) and a novel object (B) at the same position for $5 \mathrm{~min}$. Behavioural parameters were recorded by a video camera set on top of the arena and data were analyzed using Ethovision XT 11 software (Noldus). The discrimination index is calculated as the ratio of time to explore the novel object to total exploring time on both objects.

\section{$Y$ maze}

Modified version of $\mathrm{Y}$ maze test was performed as described previously, with modifications, in white polypropylene walls with three arms $(10 \times 40 \times 16 \mathrm{~cm})[37,38]$. This test comprises a sample phase trial and a test phase trial. In the sample phase trial, mice were placed in the maze with one of $3 \mathrm{arms}$ closed, and allowed to freely explore for $6 \mathrm{~min}$. Chambers were cleaned with $70 \%$ ethanol before and after each use. $6 \mathrm{~h}$ after the sample phase trial, mice were allowed to freely explore the field of maze with 3 arms opened for $6 \mathrm{~min}$ in the test phase trial. The arm previously closed in the sample phase trial was defined as the novel arm. Behavioural parameters were recorded by a video camera and time spent in novel arm were analyzed using Ethovision XT 11 software (Noldus).

\section{Open field}

The Open field task was performed as described previously in a large square chamber [39]. During the test, mice were placed in a corner square with its head facing the corner of the open field apparatus, and were allowed to explore for $8 \mathrm{~min}$ to record its exploratory activities. Chambers were cleaned with $70 \%$ ethanol before and after each use. Behavioural parameters were recorded by a video camera and data were analyzed using Ethovision XT 11 software (Noldus). 


\section{Quantification and statistical analysis}

All quantified data represent an average of at least triplicate samples. Error bars represent standard error of the mean. Statistical significance was determined by Student's $t$-test or two-way ANOVA in GraphPad Prism 5.0. $P<0.05$ was considered significant (indicated by an asterisk in the figures), $P<0.01$ (indicated by two asterisks in the figures), $P<0.001$ (indicated by three asterisks in the figures), n.s. not significant.

\section{Results}

\section{L-DL shows an age-dependent decrease in the brain}

hnRNP DL (DL) is a highly conserved nuclear RNA binding protein located in the genomic position $4 \mathrm{q} 21$ [40]. Two DL transcripts have been identified previously [41], which are translated into long- and short-isoform of DL proteins, namely L-DL and S-DL, with molecular weights of $53 \mathrm{kDa}$ and $38 \mathrm{kDa}$ respectively (Fig. S1a). To investigate their expression patterns upon aging progression, we assessed the levels of L-DL and S-DL in the hippocampus of 3-month-old mice (young) and 24month-old mice (aged). We found a significant reduction of L-DL, but not S-DL, in aged mouse hippocampus (Fig. 1a, b). Moreover, L-DL was preferentially expressed in neurons and its expression was almost undetectable in astrocytes (Fig. 1c, d). This neuronal localization of LDL was also confirmed by immunostaining (Fig. 1e). Notably, L-DL was predominantly localized to the nucleus, as demonstrated by subcellular fractionation and immunostaining (Fig. 1f, g). These findings suggest that L-DL is predominantly localized to neuronal nuclei and displays an age-dependent reduction in the hippocampus of mouse brain.

\section{Loss of L-DL in the hippocampus leads to cognitive decline in mice}

To determine the function of L-DL in cognition, we next conducted L-DL knockdown (KD) in the CA1 region of hippocampus of 8 weeks-old C57BL/6 J wild-type (WT) mice, using AAV delivered shRNA technology. We injected multiple L-DL shRNA sequences into the hippocampus of WT mouse brains, and KD efficiency was assessed by examining the levels of L-DL in the injected brains (Fig. 2a, b and Fig. S1b, c). We next conducted a series of behavioural tests to assess the cognitive function of these mice. In the Morris water maze task, mice with reduced L-DL expression spent significantly longer time to find the hidden platform comparing to control mice during the training phase (Fig. 2c). In the probe trial, these mice also showed fewer platform crossings and spent less time in the target quadrant (Fig. $2 \mathrm{~d}-\mathrm{f}$ ). In the novel object recognition task, L-DL KD mice spent less time to explore the novel objects (Fig. $2 \mathrm{~g}$ ). These results indicate that L-DL KD mice show defective spatial and contextual memory. Notably, L-DL $\mathrm{KD}$ and control mice exhibited similar spontaneous locomotor activity and anxiety-like behaviours, as indicated by the open field task, ruling out the effect of locomotor activity and anxiety on the readout of the Morris water maze test (Fig. 2h, i). Taken together, these findings demonstrate that L-DL is tightly associated to cognitive function in mice.

\section{L-DL is an essential component of nuclear speckle}

To identify L-DL binding proteins, we next performed affinity-precipitation (AP), followed by SDS-PAGE and mass spectrometry (MS) (Fig. 3a). Intriguingly, gene ontology (GO) analyses showed that L-DL associated proteins are mostly nuclear speckle proteins (Fig. 3b). We therefore examined the subcellular localization of LDL and found that L-DL was co-localized with nuclear speckle markers SC35, SON and RBM25, demonstrating that L-DL is specifically localized to nuclear speckles (Fig. 3c). No associations of L-DL with NPM1, a nucleolar protein; with promyelocytic leukemia protein (PML), a PML body marker; and with SMN, a Cajal body marker, were detected by immunostaining, suggesting that L-DL was not localized to those nuclear bodies (Fig. 3d). GST-pulldown and co-AP assays confirmed the association of L-DL with the speckle component proteins SC35 and RBM25 (Fig. 3e, f). Our findings demonstrate that L-DL is preferentially localized to nuclear speckles. We also examined the subcellular localization of other hnRNP members by immunostaining and found that hnRNP A1, hnRNP C, hnRNP K and hnRNP U showed homogeneous distribution within the nucleus (Fig. S2a).

Interestingly, L-DL knockout (KO) resulted in cellular expression pattern changes of SC35 and SON from densely packed to diffusely distributed, suggesting that L-DL deficiency leads to disruption of nuclear speckle structure (Fig. 3g, h). These findings indicate that L-DL is an essential component and is important for maintaining the integrity of nuclear speckles by interacting with other key speckle proteins such as SC35 and SON.

\section{Downregulation of L-DL induces alternative splicing changes in the brain}

Nuclear speckle is highly enriched with RNA processing factors and its functions are predominantly linked to pre-mRNA splicing [42]. The nuclear speckle localization of L-DL prompted us to investigate the function of L-DL in RNA splicing. We next assessed the splicing activity by using an intron-containing luciferase reporter and found a significant reduction in splicing activity in L-DL depleted N2a cells (KO) [24] 


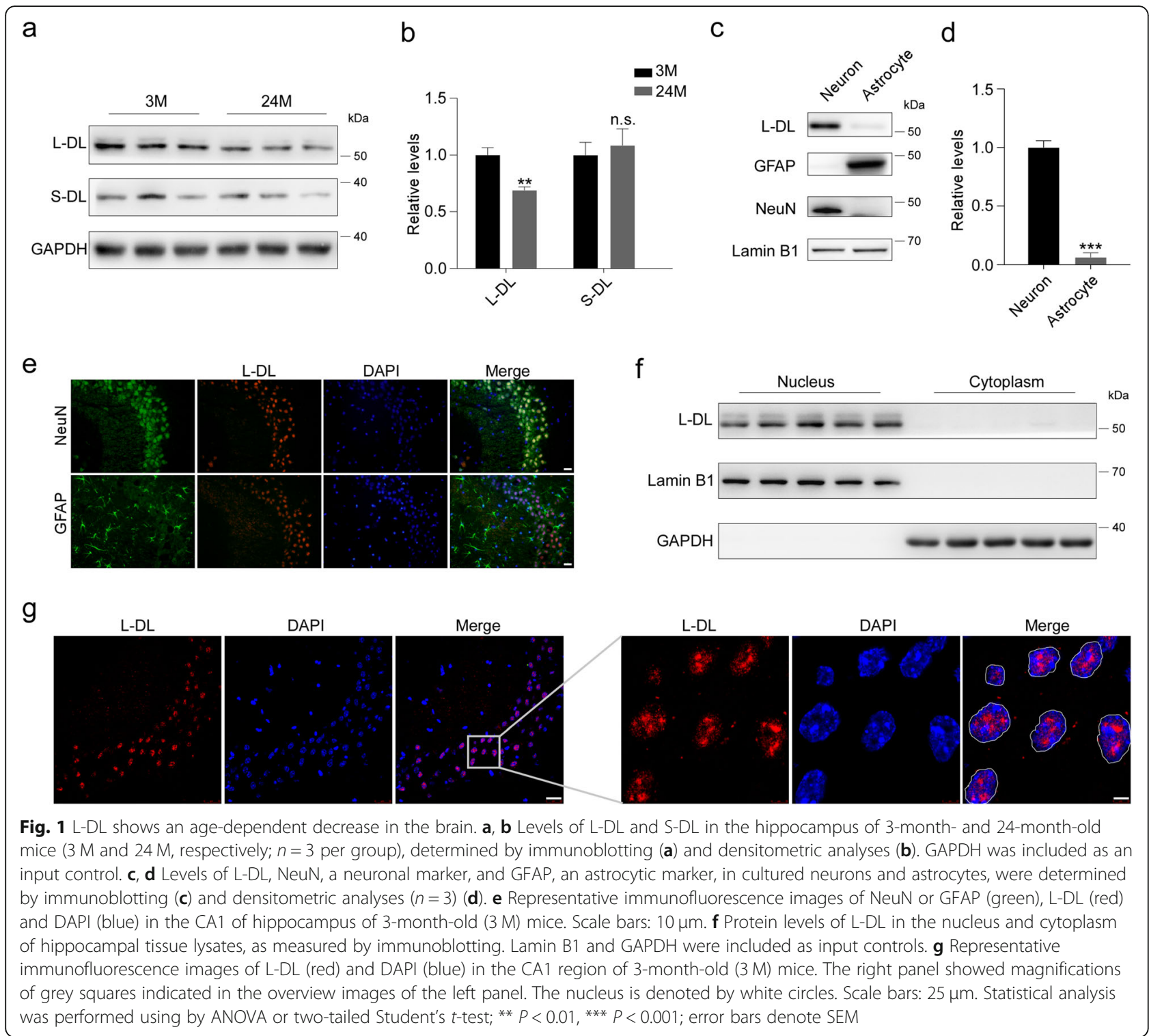

(Fig. 4a, b), suggesting that L-DL participates in RNA splicing process.

We next investigated whether L-DL regulates cognition through modulating RNA splicing. Hippocampal tissues from control and L-DL KD mice were subjected to RNA sequencing and subsequent splicing analyses. Splicing analyses demonstrated that a total of 2,181 splicing events displayed significant splicing pattern changes in L-DL KD brains, wherein exon skipping was the most dominant event (71.94\%); other splicing events included intron retention (10.22\%), mutually exclusive exon inclusions, retained introns, alternative $5^{\prime}$ splice sites, and alternative $3^{\prime}$ splice sites (17.84\%) (Fig. 4c-d). We used "percent spliced in" (PSI) values to define the alternative splicing levels of each gene segment by the rMATs software as described previously [31]. We found that $38.93 \%$ of these gene segments showed increased inclusion ( $\mathrm{PSI}_{\mathrm{L}-\mathrm{DL}} \mathrm{KD}^{-}-\mathrm{PSI}_{\mathrm{CTRL}}>0, P<0.001$ ) and $61.07 \%$ showed increased exclusion ( $\mathrm{PSI}_{\mathrm{L}-\mathrm{DL}} \mathrm{KD}^{-}-\mathrm{PSI}_{\mathrm{CTRL}}<0$, $P<0.001$ ) in L-DL KD brains (Fig. 4e-f). Of note, segment exclusion in L-DL KD brains occurred more often in exon skipping, compared to intron retention and other splicing events. Conversely, segment inclusion occurred more often in intron retention and other splicing events than exon skipping in L-DL KD brains (Fig. 4e-f). All these findings demonstrate that L-DL deficiency leads to significant changes in multiple alternative splicing events in the brain.

A substantial change in gene expression has been observed in the brain of aged mice [43] and AD model 


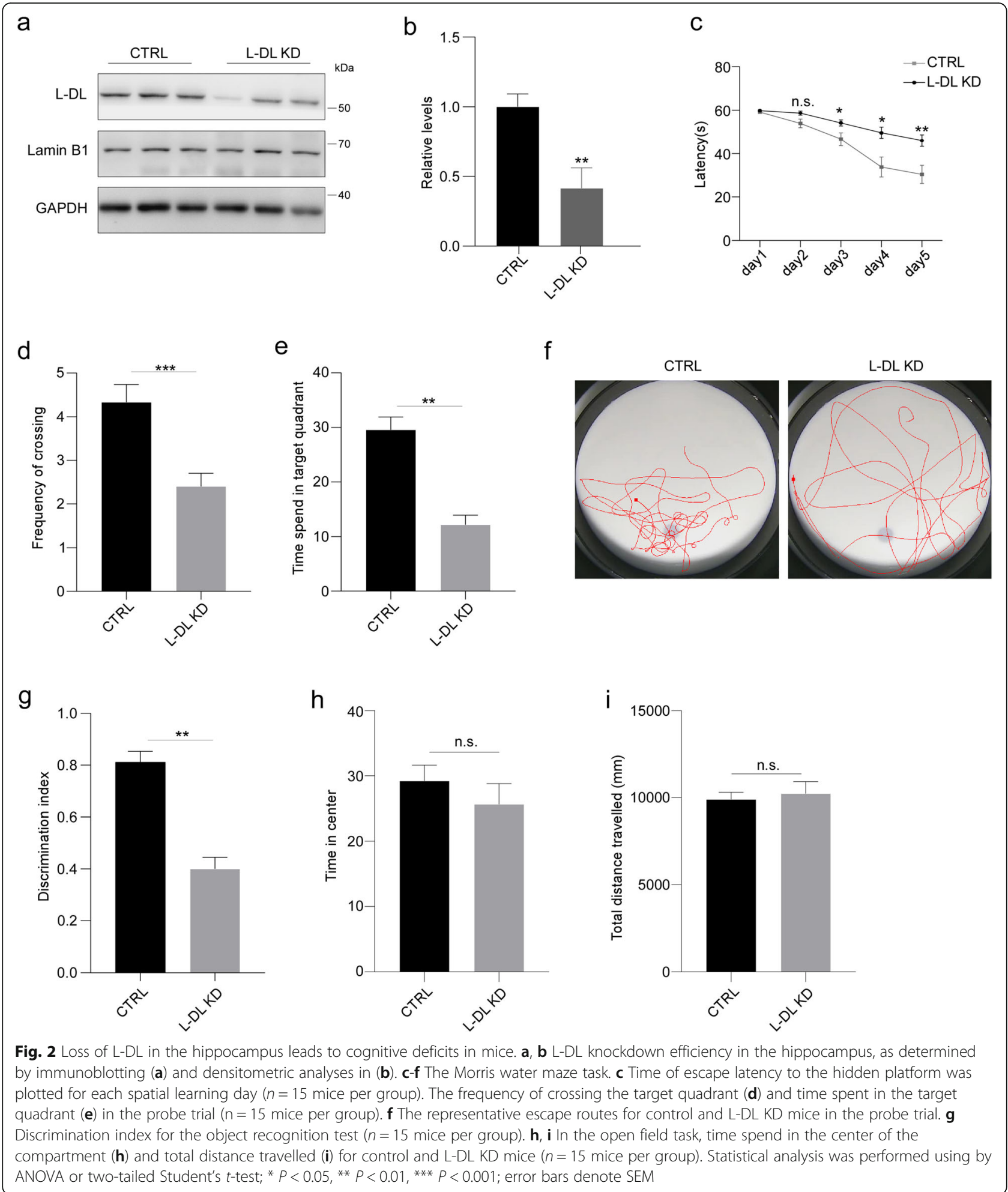

mice (APP/PS1) [44, 45]. To ascertain the relationship between the previously identified differentially expressed genes (DEGs) in aged vs young or AD vs control brains and genes with altered alternative splicing patterns identified in the L-DL KD mouse brain, we next conducted overlapping analysis: DEGs were pulled out from (1) RNA-seq data of young vs old mouse brains (GSE129788), (2) RNA-seq data of APP/PS1 vs WT 
a

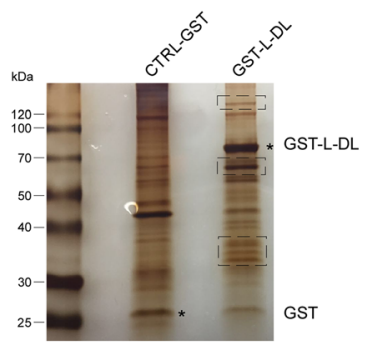

C

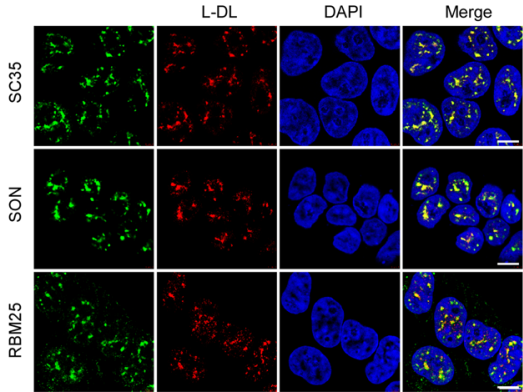

b

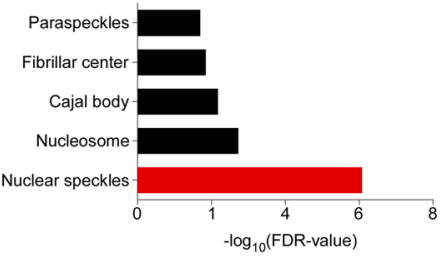

d

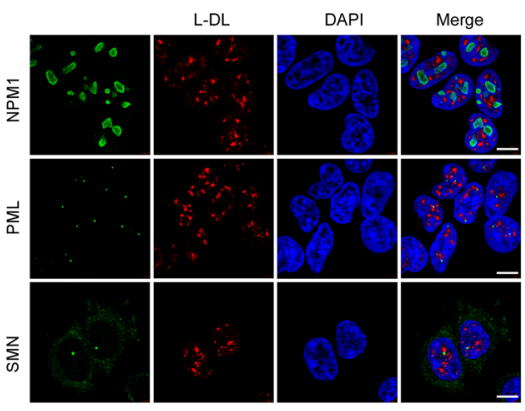

g
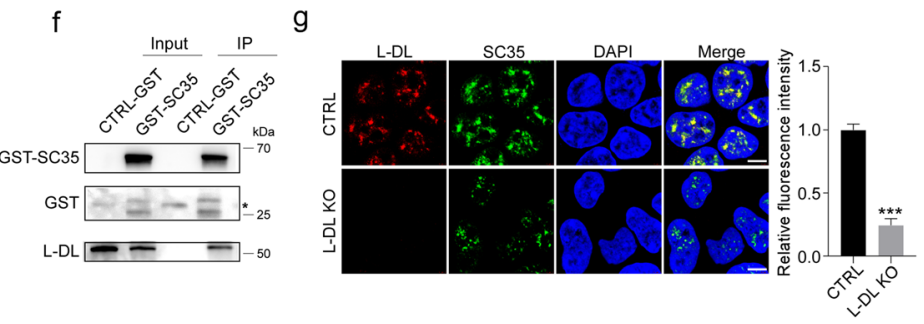

h

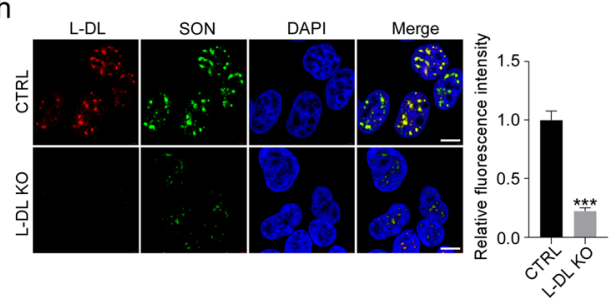

Fig. 3 L-DL is an essential structural component of nuclear speckle. a Control GST (CTRL-GST) and GST tagged L-DL (GST-L-DL) were introduced into 293 T cells, followed by pull-down with GST agarose beads. L-DL associated proteins were subjected to silver staining, black square denoted bands were subjected to mass spectrometry analysis. b Cellular component terms in the gene ontology (GO) analysis for L-DL associated proteins identified in mass spectrometry. c Representative immunofluorescence images of L-DL (red) and SC35 (green), L-DL (red) and SON (green), L-DL (red) and RBM25 (green), and DAPI (blue) in 293T cells. Scale bars: $10 \mu \mathrm{m}$. d Representative immunofluorescence images of L-DL (red) and NPM1 (green), L-DL (red) and PML (green), L-DL (red) and SMN (green), and DAPI (blue) in 293T cells. Scale bars: $10 \mu \mathrm{m}$. e CTRL-GST and GST-L-DL were introduced into 293T cells, followed by pull-down with GST agarose beads. L-DL associated proteins were subjected to immunoblotting with anti-SC35, anti-RBM25, anti-NPM1 and anti-PML antibodies. f CTRL-GST and GST-SC35 were introduced into 293T cells, followed by pull-down with GST agarose beads. SC35 associated proteins were subjected to immunoblotting with anti-L-DL antibody. $\mathbf{g}$ Left: representative immunofluorescence images of L-DL (red), SC35 (green) and DAPI (blue) in control and L-DL knockout (KO) 293T cells. Scale bars: $10 \mu$ m. Right: Densitometric analyses of SC35 fluorescence density. $\mathbf{h}$ Left: representative immunofluorescence images of L-DL (red), SON (green) and DAPI (blue) in control and L-DL KO 293T cells. Scale bars: $10 \mu \mathrm{m}$. Right: densitometric analyses of SON fluorescence density. Statistical analysis was performed using two-tailed Student's $t$-test; ${ }^{* *} P<0.001$; error bars denote SEM

mouse brains (GSE132177), and (3) proteomic data of human AD brains [45]. We found that a total of 127 genes $(4.9 \%)$ corresponding to intersections of genes with changed alternative splicing pattern in L-DL KD mouse brains and DEGs in aged vs young mouse brains (Fig. 4g). A total of 136 genes (5.9\%) corresponding to 


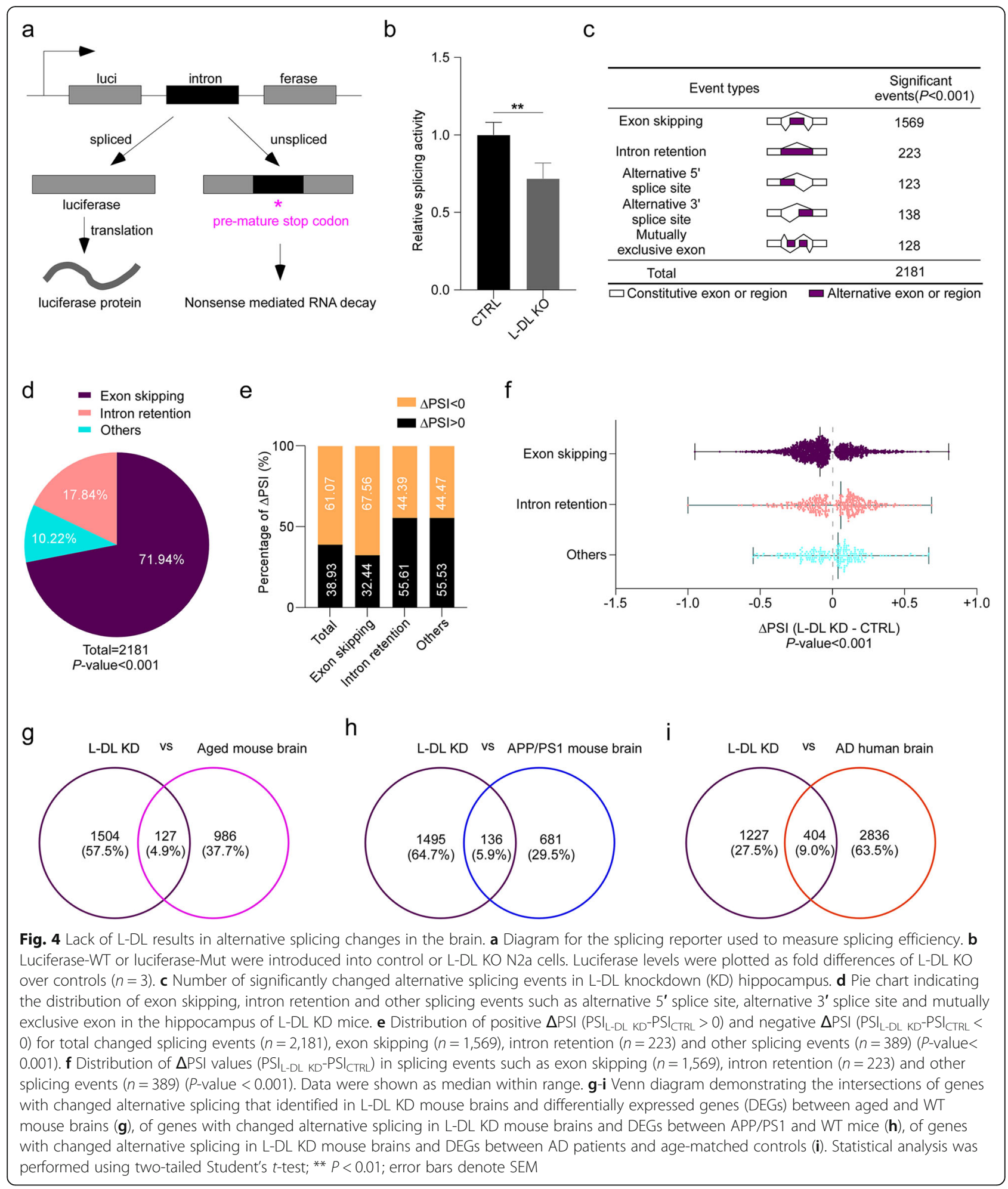


intersections of genes with changed alternative splicing pattern in L-DL KD mouse brains and DEGs in AD vs WT mouse brains (Fig. 4h). Importantly, we uncovered a total of 404 genes $(9 \%)$ corresponding to intersections of genes with changed alternative splicing pattern in L-DL $\mathrm{KD}$ mouse brains and DEGs in $\mathrm{AD}$ vs control human brains (Fig. 4i). These findings demonstrate that L-DL downregulation-induced splicing changes likely contribute to aging and age-related diseases.

\section{L-DL deficiency impairs U2 spliceosome-dependent RNA splicing}

GO analyses showed that L-DL associated proteins identified in MS exhibited an enriched functional annotation related to RNA binding and RNA splicing process (Fig. 5a, b). Network analysis on L-DL associated proteins enriched in "mRNA splicing via spliceosome" term indicated that L-DL interacts with multiple components of U2 spliceosome complex (Fig. 5c). U2 snRNP is a core component of the spliceosome, and SF3B is a core component of U2 snRNP [46]. U2AF is required for U2 snRNP binding and splicing complex assembly [3, 47], wherein U2AF35 binds to the $3^{\prime}$ splice sites and U2AF65 binds to the polypyrimidine tract of premRNAs (Fig. 5d). The association of L-DL and U2 snRNPs was validated by Co-AP (Fig. 5e). In particular, L-DL was found to associate with U2AF35, U2AF65 and SF3B3, but not with SF3B1 (Fig. 5e). The association of L-DL and U2AF65 was further confirmed by Co-IP (Fig. 5f). In addition, both SF3B1 and SF3B3 are also associated with U2AF65 (Fig. 5f). Importantly, L-DL deficiency substantially reduced the association of U2AF65 with SF3B1 and SF3B3 (Fig. 5g, h). These findings indicate that L-DL is an integral and essential component of U2 snRNP, and loss of L-DL may disrupt loading of U2 snRNP on pre-mRNAs. Notably, we also identified multiple hnRNPs, such as hnRNP A1, hnRNP C, hnRNP U and hnRNP $\mathrm{K}$ as L-DL associated proteins in MS (Fig. 5c). Given that these identified hnRNPs are reportedly involved in RNA splicing process [48], we next conducted Co-AP to validate the association of L-DL and these hnRNPs. We found that L-DL indeed was associated with hnRNP A1, hnRNP C, hnRNP $U$ and hnRNP $\mathrm{K}$, further supporting the involvement of L-DL in RNA splicing process (Fig. S2b).

\section{L-DL regulates alternative splicing of genes involved in synaptic function}

Given that a loss of L-DL leads to cognitive decline in WT mice (Fig. 2c-g), we postulated that L-DL regulates cognitive function through modulating alternative splicing and expression of genes that are involved in synaptic function. Indeed, KEGG pathway and GO analyses revealed significant changes in alternative splicing of genes that were closely related to synaptic function and cognitive process (Fig. S3a-c). In addition, cellular component analyses revealed significant changes in alternative splicing of genes related to multiple cellular structures of neuronal cells, including postsynaptic density, synapse, cytoskeleton and dendritic spine (Fig. 6a). Some of welldefined gene-encoded productss and their cellular localizations were illustrated in Fig. 6b, e.g., dendrite and synapse related genes such as cell adhesion molecule 1 (CADM1), which is a synaptic cell adhesion molecule that regulates synaptogenesis [49]; G protein-coupled receptor kinase interacting protein 2 (GIT2), which regulates cytoskeletal structure and presynaptic neurotransmitter release [50, 51]; cell adhesion molecule L1 like (CHL1), which is accumulated in presynaptic membranes and regulates synaptic activity and plasticity [52]; calcium/calmodulindependent serine protein kinase (CASK), which is a synapse scaffolding protein that is involved in synapse formation and function [53]; AGRIN, a heparan sulfate proteoglycan that promotes the formation of excitatory synapses [54]; G protein-coupled receptor kinase interacting protein 1 (GIT1), which regulates microtubule assembly and promotes synapse formation and maintenance [55]; Src Substrate Cortactin (CTTN), which is involved in actin polymerization and activity-dependent synaptic plasticity [56]; PSD95, a postsynaptic scaffolding protein that is required for activity-driven synapse stabilization [57]; Adhesion G protein-coupled receptor L1 (ADGRL1), which is involved in synapse formation and brain development [58]. In addition, some of the genes are highly related to cytoskeleton or microtubule formation, e.g., polyphosphoinositide phosphatase synaptojanin 1 (SYNJ1), which participates in actin cytoskeleton polymerization and synaptic vesicle recycling [59]; erythrocyte membrane protein band 4.1 like 3 (EPB41L3), which is related to actin binding and protein-protein interactions at synapses [60, 61]; microtubule-associated protein tau (MAPT) gene, which encodes tau protein that is involved in axonal transport, synaptic plasticity and function [62]. Of note, hippocampus-dependent memory is tightly associated with microtubules dynamics [63].

We next verified the alternative splicing patterns of dendrite and synapse related genes, and observed significant decreased skipping over exon 8 of CADM1, over exon 15 of GIT2, significant increased skipping over exon 24 of CHL1, over exon 19 of CASK, over exon 34 of AGRIN, over exon 8 of GIT1, over exon 11 of CTTN, and over exon 18 of PSD95 and significant increased intron retention over intron 19 of ADGRL1 (Fig. 6c). We also assessed the alternative splicing patterns of cytoskeleton-related genes, and found significant increased skipping over exon 28 of SYNJ1, over exon 14 of EPB41L3 and decreased skipping over exon 4A of MAPT (Fig. 6d). Importantly, calmodulin kinase-like 


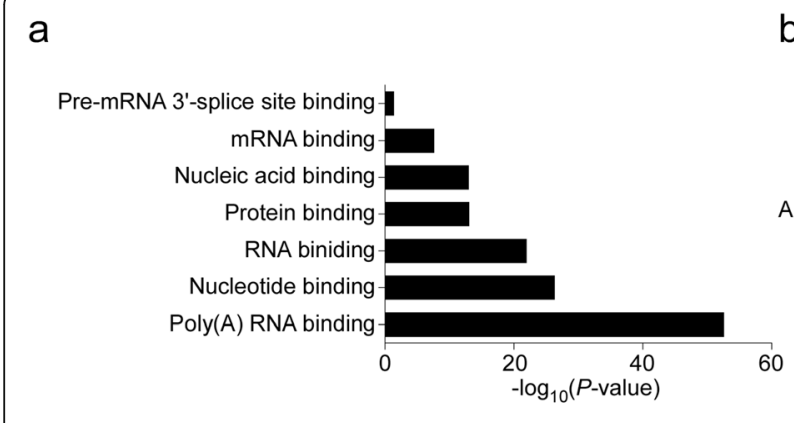

C
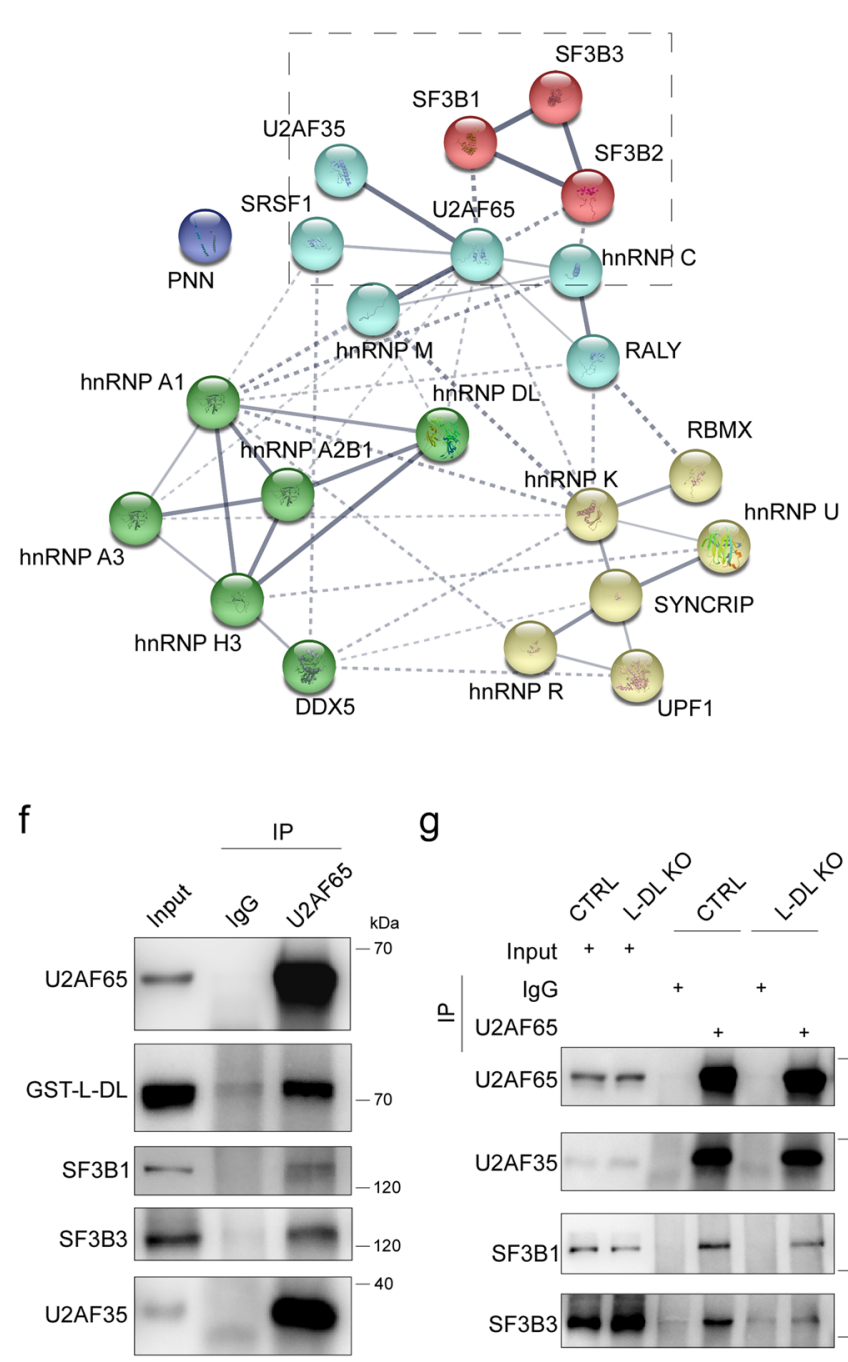

b

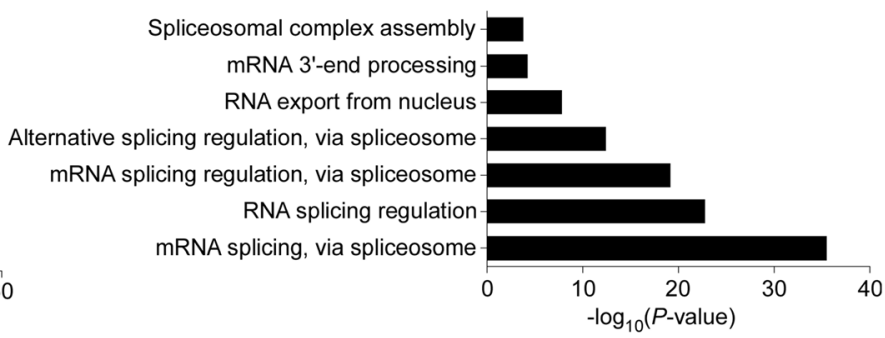

d

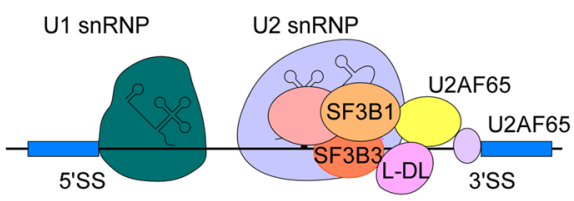

e

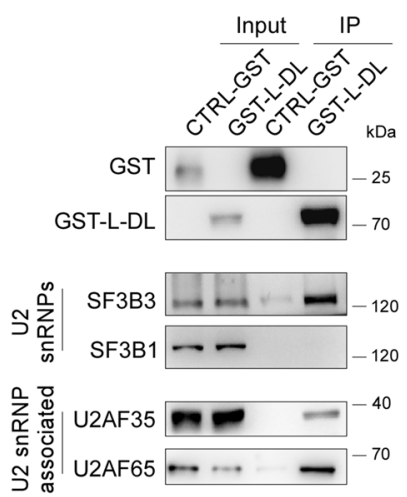

h

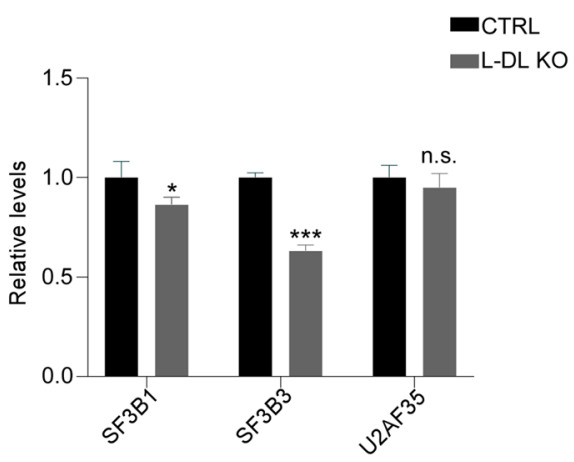

Fig. 5 L-DL deficiency impairs U2 spliceosome dependent RNA splicing. (a-b) Molecular function (a) and biological process (b) terms in GO analysis for L-DL associated proteins identified in mass spectrometry. c Protein-protein interaction (PPI) network for L-DL associated proteins (PPI enrichment $P<1.0 \mathrm{E}-16)$. The network clustering is based on k-mean clustering and each cluster is labelled with a distinct colour. $\mathbf{d}$ A drawing of U2 spliceosome assembly on pre-mRNAs. 5'SS or 3'SS indicate 5' or 3' splicing sites, respectively. e CTRL-GST or GST-L-DL were introduced into 293 T cells, followed by pull-down with GST agarose beads. L-DL associated proteins were determined by immunoblotting. f GST-L-DL was introduced into 293T cells, followed by immunoprecipitation with anti-U2AF65 antibody. Levels of U2AF65 associated proteins were measured by immunoblotting. $\mathbf{g}$, h Control or L-DL KO N2a cell lysates were subjected to immunoprecipitation with anti-U2AF65 antibody. Levels of U2AF65 associated proteins were measured by immunoblotting $(\mathbf{g})$ and densitometric analyses $(n=3)(\mathbf{h})$. Statistical analysis was performed using twotailed Student's $t$-test; * $P<0.05,{ }^{* * * * *} P<0.001$; error bars denote SEM 


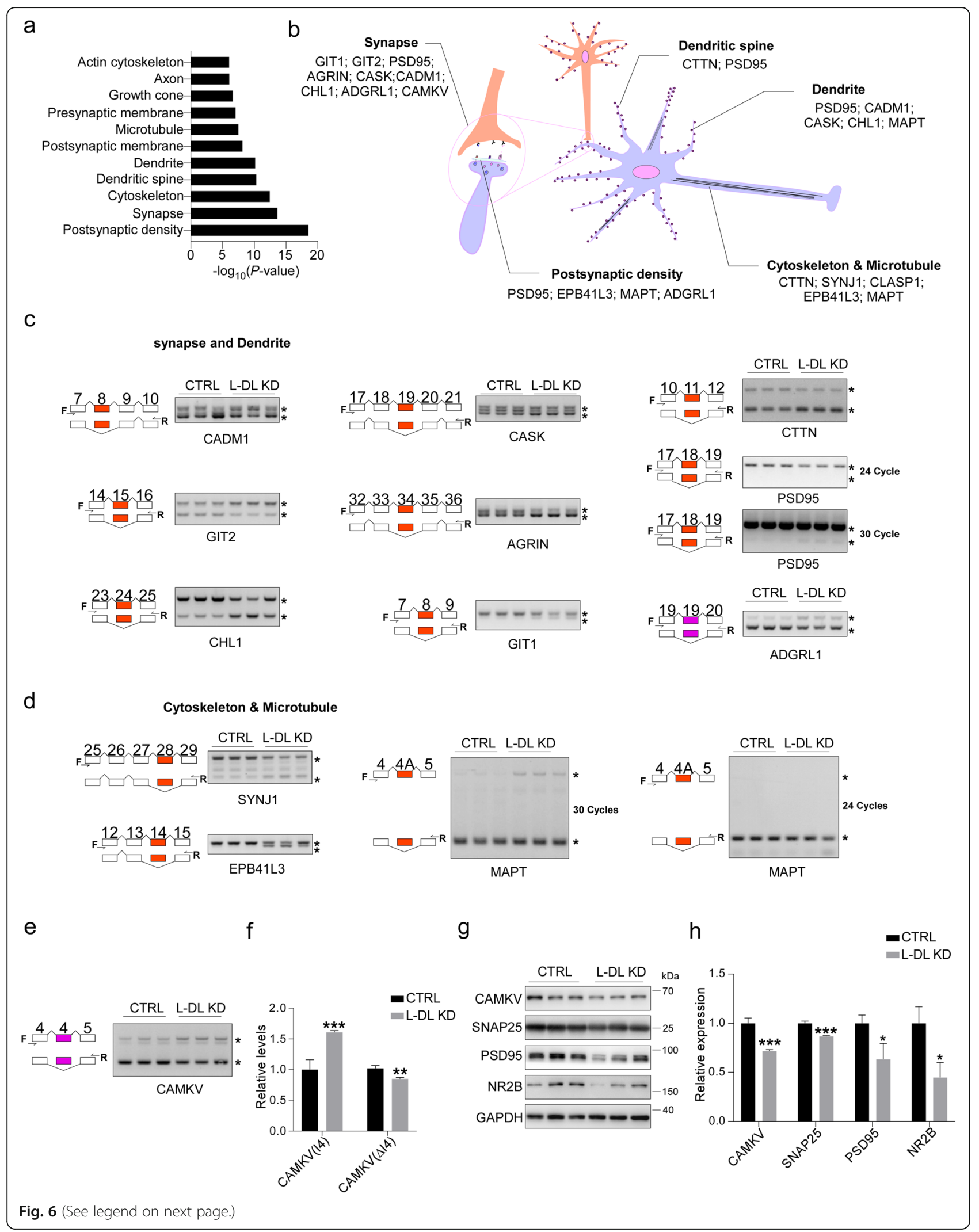


(See figure on previous page.)

Fig. 6 L-DL regulates cytoskeleton- and synapse-related gene expressions via modulating their alternative splicing. a Cellular component terms for genes with changed alternative splicing in the hippocampus of L-DL knockdown (KD) mice in GO analysis $(n=1,631, P<0.001)$. b Diagram for cellular localization of synapse-, dendrite- and cytoskeleton-related proteins, with their genes undergoing aberrant alternative splicing in neurons. c, d Alternative splicing products of CADM1, GIT2, CHL1, CASK, AGRIN, GIT1, CTTN, PSD95, ADGRL1, SYNJ1, EPB41L3 and MAPT gene, determined by RT-PCR in the hippocampus of control and L-DL KD mice $(n=3)$. * indicates spliced variants, F and R denote primers used for RT-PCR. 24 cycles or 30 cycles were used to detect higher abundant and lower abundant splicing products, respectively. $\mathbf{e}, \mathbf{f}$ Alternative splicing products of CAMKV determined by RT-PCR (e) and densitometric analyses ( $\mathbf{f}$ ) in the hippocampus of control and L-DL KD mice $(n=3)$. 14, intron 4 retention; $\Delta \mid 4$, intron 4 exclusion. $\mathbf{g}$, $\mathbf{h}$ Protein levels of CAMKV, SNAP25, PSD95, NR2B in the hippocampus of control and L-DL KD mice, measured by immunoblotting $(\mathbf{g})$ and densitometric analyses (h). GAPDH was included as an input control. Statistical analysis was performed using two-tailed Student's t-test; ${ }^{*} P<0.05,{ }^{*} P<0.01$, ${ }^{* *} P<0.001$; error bars denote the SEM

vesicle-associated (CAMKV) gene, whose deficiency in CA1 pyramidal neurons impairs synaptic plasticity and spatial memory [64], showed a significant increase in intron 4 retention, leading to reduced production of CAMKV protein (Fig. 6e-h). We further found that the levels of synaptic proteins SNAP25, PSD95, and NMDA receptor subunit NR2B were significantly decreased in the hippocampus of L-DL KD mice (Fig. 6g, h). These findings strongly indicate that L-DL regulates cognition via modulating the alternative splicing of genes that are involved in synaptic function.

\section{L-DL improves cognitive function in $A D$ mice}

Given that L-DL is decreased in aged mouse brains and downregulation of L-DL impairs mouse memory, we next examined the potential role of L-DL in age-related neurodegenerative diseases, especially $\mathrm{AD}$. We first observed a significant reduction of L-DL in the hippocampus of APP/PS1 mice (Fig. 7a, b), and therefore conducted L-DL overexpression (OE) or knockdown (KD) in the hippocampus of APP/PS1 mice. L-DL overexpression was driven by CamKII promoter, and L-DL KD was achieved by target shRNA expression driven by $\mathrm{H} 1$ promoter. AAV-mediated delivery was achieved via brain injection into the bilateral CA1 areas of the hippocampus in APP/PS1 mice at 6 months of age. L-DL expression was confirmed by immunoblotting 4 weeks after the injection (Fig. 7c-f). Behavioural assays showed that L-DL OE significantly improved contextual memory in APP/PS1 mice, as demonstrated by increased discrimination index in novel object recognition task; and increased time spending in the novel arm in Y maze task, compared to control APP/PS1 mice (Fig. 7g, i). L-DL OE did not affect locomotor activity and anxiety in APP/PS1 mice (Fig. S4a, c). Conversely, APP/PS1 mice with L-DL KD displayed deteriorated contextual memory, as demonstrated by decreased discrimination index in novel object recognition task and decreased time spending in novel arm in $\mathrm{Y}$ maze, compared to control APP/PS1 mice (Fig. 7h, j). APP/PS1 mice with L-DL KD showed no difference in their locomotor activity and anxiety, when compared to control mice (Fig. S4b, d).

\section{L-DL improves cognition in AD mice via modulating} alternative splicing and expression of synaptic genes To investigate how L-DL OE leads to improved cognition in APP/PS1 mice, we next examined the alternative splicing pattern of CAMKV, and found that L-DL OE in APP/PS1 mice led to significantly decreased intron 4 retention and increased production of CAMKV protein (Fig. 8a, b, e, f). Moreover, synaptic proteins SNAP25, PSD95, NMDA receptor NR2B also showed significantly increased expression in L-DL OE APP/PS1 mouse hippocampus (Fig. 8e, f). In contrast, L-DL KD in APP/ PS1 mice resulted in significantly increased intron 4 retention and consequently reduced production of CAMKV protein (Fig. 8c, d, g, h). Similarly, SNAP25, PSD95 and NR2B were also significantly decreased in the hippocampus of APP/PS1 mice with L-DL KD (Fig. $8 \mathrm{~g}, \mathrm{~h}$ ). Taken together, upregulation of L-DL improves the cognitive function of $\mathrm{AD}$ mice via modulating alternative splicing and subsequent synaptic protein production.

\section{Discussion}

Alternative splicing of RNAs persists across life span, affecting more than a third of genes linked to neural function in human brains [7]. Mounting evidence has shown that significant changes in alternative splicing occur during aging progression and neurodegenerative diseases [11]. However, how these splicing changes affect cognition upon progression of aging and agerelated neurodegenerative diseases remains elusive. Here we demonstrate that L-DL regulates cognition via modulating the alternative splicing patterns of cytoskeleton- and synapse-related genes. We first demonstrate that L-DL expression is substantially decreased in the hippocampus of aged and AD mouse brains. We also uncover that KD of L-DL in the hippocampus deteriorates cognition in WT and APP/ PS1 mice, whereas introduction of L-DL into the hippocampus of APP/PS1 mice significantly improves the cognition of these mice.

Nuclear speckles are considered a storage site for splicing factors and therefore are functionally involved in splicing process [19]. Intriguingly, L-DL is specifically 


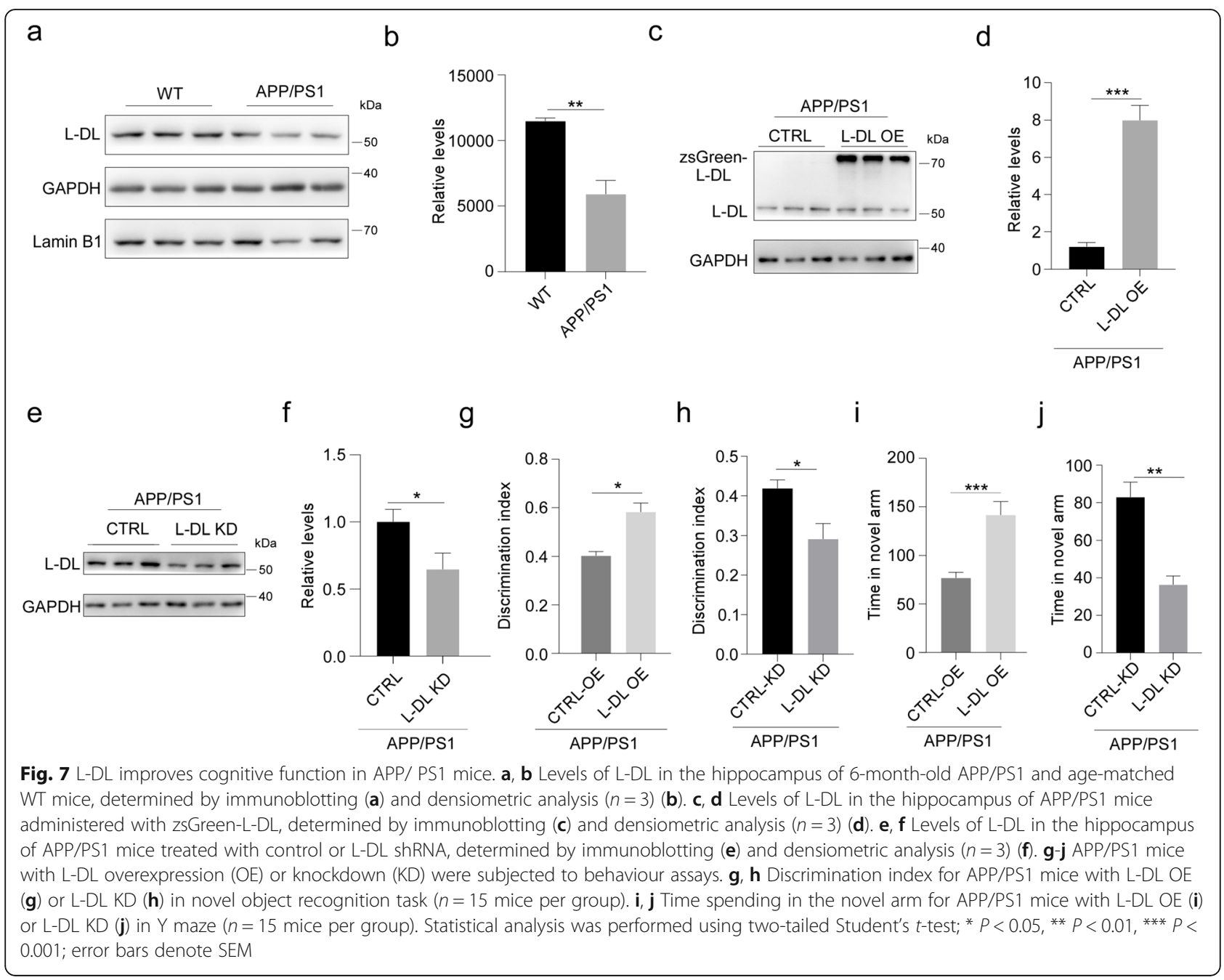

localized to nuclear speckles and L-DL KD leads to disrupted nuclear speckle structure, suggesting L-DL serves as a structural component and may participate in RNA splicing process. The pre-mRNA splicing process is executed by the spliceosome, a dynamic protein and RNA complex in eukaryotes [1]. Spliceosomes possess great plasticity in RNA substrate recognition and this process is mainly influenced by RNA binding proteins (RBPs). hnRNPs represent a large family of RBPs that are extensively involved in the regulation of RNA splicing. For instance, polypyrimidine tract binding proteins (PTBPs) and hnRNP $\mathrm{K}$, which bind to U2AF65 with similar binding motifs, regulate U2AF65-mediated recognition of U2 spliceosome at the 3' splice sites and consequently influence RNA splicing $[65,66]$. Additionally, hnRNP U directly binds to snRNAs and regulates the conversion of $15 \mathrm{~S}$ U2 snRNP to $17 \mathrm{~S}$ U2 snRNP to modulate U2 snRNP maturation and RNA splicing [67]. Here, we demonstrate that L-DL participates in RNA splicing process via modulating the loading of U2 snRNPmediated spliceosome on the target RNAs.
Consequently, the splicing activity is significantly decreased in L-DL deficient cells.

Regulatory role of hnRNP DL in RNA alternative splicing has been demonstrated previously in tumorigenesis [68], however, its role in the brain remains elusive. Our results demonstrate that L-DL is highly expressed in neurons and its expression is significantly reduced not only in aged mouse brains, but also in AD mouse brains. In support of these conclusions, levels of hnRNP DL are found reduced in both aged and AD human brains [69]. We also demonstrate that multiple alternative splicing changes occur in the hippocampus of L-DL KD mice. Importantly, exon skipping is the most dominant type of alternative splicing events. Moreover, among intron retention events, most of the segments showed increased inclusion (55.61\%), which is consistent with splicing changes reported previously in aging brains [7]. Neuronal plasticity changes are tightly associated with RNA splicing changes during aging and age-related diseases $[7,13,14]$. In addition, previous studies have reported that synaptic plasticity, which is associated with 


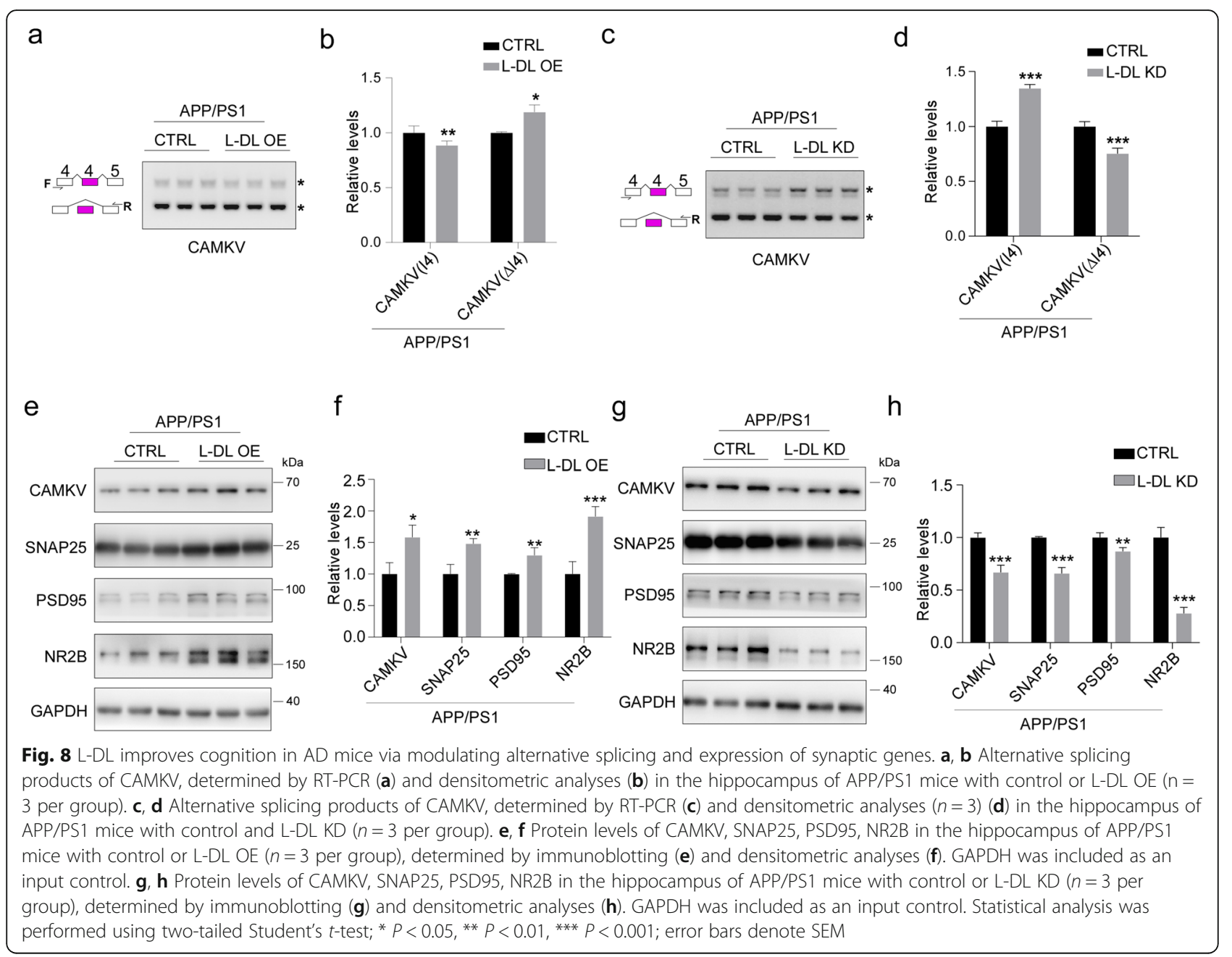

hippocampus-dependent memory formation, is also regulated by microtubules dynamics [63]. Consistently, GO term analysis showed that genes with exon skipping in the hippocampus of L-DL KD mice are functionally related to cytoskeleton organization and synaptic functions.

Importantly, introduction of L-DL into the hippocampus of APP/PS1 mice significantly improves the cognitive function. Mechanistically, we demonstrate that LDL regulates CAMKV expression in the hippocampus of mice by regulating $C A M K V$ intron 4 alternative splicing. In support of this, previous reports have shown that CAMKV deficiency results in abnormal dendritic spine density, synaptic transmission in cultural hippocampal neurons [64]. In addition, hippocampal CAMKV knockdown mice exhibited attenuation in late-phase long-term potentiation (LTP) and memory deficits [64]. These findings support that L-DL regulates cognitive process through regulating the alternative splicing of $C A M K V$ and its expression during brain aging and neurodegenerative diseases. Notably, levels of multiple synaptic proteins are down-regulated in APP/PS1 mouse brains [70]. We uncover that introduction of L-DL promotes expression of multiple synaptic genes in AD mouse brains, including CAMKV, SNAP25, PSD95 and NR2B. We therefore speculate that L-DL regulates the expression of multiple synapse- and cytoskeleton-related genes via modulating their RNA splicing process in AD brains of -.CAMKV Therefore, L-DL-mediated improvement in cognition in APP/PS1 mice is likely due to the restoration of multiple synaptic and cytoskeletal gene expression, beyond $C A M K V$, via changing the alternative splicing patterns of these genes.

\section{Conclusions}

Aberrant alternative splicing changes are tightly associated with brain aging and age-related neurodegenerative diseases, however what triggers these aging associated splicing abnormalities and the regulatory mechanism behind it remain largely elusive. Here, we identify a RNA binding protein hnRNP L-DL, whose expression displays an age- and $\mathrm{AD}$-dependent reduction in the brain. 
Notably, L-DL is preferentially localized to nuclear speckles, where L-DL regulates the alternative splicing of selected synapse- and cytoskeleton-related genes. Consequently, these gene expression are altered by L-DL. Importantly, L-DL introduction substantially improves cognitive decline in AD mice. Taken together, our study defines nuclear speckle specific protein hnRNP DL as a critical molecule linking RNA splicing and aging/AD associated cognitive decline, shedding light on a potential therapeutic approach for cognitive decline in aged and $\mathrm{AD}$ brains via correcting aberrant RNA splicing.

\begin{abstract}
Abbreviations
hnRNPs: Heterogeneous nuclear ribonucleoproteins; hnRNP DL: Heterogeneous nuclear ribonucleoprotein D-like; hnRNP A1: Heterogeneous nuclear ribonucleoprotein A1; hnRNP C: Heterogeneous nuclear ribonucleoprotein $C_{;}$hnRNP $U$ : Heterogeneous nuclear ribonucleoprotein U; hnRNP K: Heterogeneous nuclear ribonucleoprotein K; L-DL: Long isoform of hnRNP DL; S-DL: Short isoform of hnRNP DL; SF3B1: Splicing factor $3 \mathrm{~b}$ subunit 1; SF3B2: Splicing factor 3b subunit 2; SF3B3: Splicing factor 3b subunit 3; U2 snRNP: U2 small nuclear ribonucleoprotein ; U2AF65: U2 auxiliary factor $65 \mathrm{kDa}$ subunit; U2AF35: U2 auxiliary factor $35 \mathrm{kDa}$ subunit; 5'SS: 5' splice sites; 3'SS: 3' splice sites; AD: Alzheimer's disease; PSD95: Postsynaptic density protein 95; PTBP1: Polypyrimidine tract binding protein 1; BACE1: Beta-secretase 1; A $\beta$ : $\beta$ amyloid; PS1: Presenilin 1; SC35: /Splicing component 35 kDa; RBM25: RNA binding motif protein 25; NPM1: Nucleophosmin 1; PML: Promyelocytic leukemia protein; SNAP25: Synaptosome associated protein 25; NR2B: Glutamate ionotropic receptor NMDA type subunit 2B; SMN: Survival of motor neuron protein ; GFAP: Glial fibrillary acidic protein; NeuN: Neuronal nuclear protein; MAPT: Microtubule associated protein Tau; PSI: Percent spliced in; DEGs: Differentially expressed genes; CADM1: Cell adhesion molecule 1; GIT1: G protein-coupled receptor kinase interacting protein 1; GIT2: G protein-coupled receptor kinase interacting protein 2; CHL1: Cell adhesion molecule L1 Like; CASK: Calcium/calmodulin-dependent serine protein kinase; CTTN: Cortactin; ADGRL1: Adhesion G protein-coupled receptor L1; SYNJ1: Synaptojanin 1; EPB41L3: Erythrocyte membrane protein band 4.1 like 3; CAMKV: Calmodulin kinase-like vesicle-associated protein; LTP: Long-term potentiation
\end{abstract}

\section{Supplementary Information}

The online version contains supplementary material available at https://doi. org/10.1186/s13024-021-00485-w.

\section{Additional file 1.}

\section{Acknowledgements}

We thank all authors for their kindly participation in this study.

\section{Authors' contributions}

Q. L. supervised the project. Q.Z., J.Z. H.X. and Q.L. conceived and designed the study. Q.Z., J.Ye, X.M., X.L., H.L., K.H., W.Z., J.Yuan. and C.W. performed experiments and analyzed data. Q.Z., J.Z., Y.Z., H.X. and Q. L. discussed and wrote the manuscript. All authors read and approved the final manuscript.

\section{Funding}

This work was supported by National Key R\&D Program of China [2020YFA0509300 to Q.L.]; National Natural Science Foundation of China grants [82125009, 31871082, 91849101 to Q.L., 92049202 to H.X., 82071185 to J.Z. and 82071213 to Y.Z.]; the Strategic Priority Research Program of the Chinese Academy of Sciences [XDB39000000 to Q.L.]; Key Research Program of Frontier Sciences of the Chinese Academy of Sciences [QYZDB-SSW-S MC035 to Q.L.]; CAS Project for Young Scientists in Basic Research [YSBR-013 to Q.L.]; and the Fundamental Research Funds for the Central Universities [to Q.L.].

\section{Availability of data and materials}

RNA-seq data used in this publication have been deposited in NCBI's Gene Expression Omnibus and are accessible through GEO Series accession number GSE169281.

\section{Declarations}

Ethics approval and consent to participate

Not applicable.

\section{Consent for publication}

All authors have reviewed the final manuscript and consent to publication.

\section{Competing interests}

The authors declare they have no completing interests.

\section{Author details}

'Institute on Aging and Brain Disorders, The First Affiliated Hospital of USTC, Hefei National Laboratory for Physical Sciences at the Microscale, Division of Life Sciences and Medicine, University of Science and Technology of China, Hefei 230026, China. ${ }^{2}$ Anhui Province Key Laboratory of Biomedical Aging Research, University of Science and Technology of China, Hefei 230026, China. ${ }^{3}$ School of Life Sciences, Division of Life Sciences and Medicine, University of Science and Technology of China, Hefei 230026, China. ${ }^{4}$ Department of Anesthesiology, The First Affiliated Hospital of USTC, Division of Life Sciences and Medicine, University of Science and Technology of China, Hefei 230001, China. ${ }^{5}$ The First Affiliated Hospital of Xiamen University, Fujian Provincial Key Laboratory of Neurodegenerative Disease and Aging Research, Institute of Neuroscience, Xiamen University, Xiamen 361000, China. ${ }^{6}$ Center for Excellence in Animal Evolution and Genetics, Chinese Academy of Sciences, Kunming 650201, China.

Received: 5 July 2021 Accepted: 12 August 2021

Published online: 22 September 2021

References

1. Fu XD, Ares M Jr. Context-dependent control of alternative splicing by RNAbinding proteins. Nat Rev Genet. 2014;15(10):689-701. https://doi.org/10.103 8/nrg3778.

2. Aebi M, Hornig H, Padgett RA, Reiser J, Weissmann C. Sequence requirements for splicing of higher eukaryotic nuclear pre-mRNA. Cell. 1986; 47(4):555-65. https://doi.org/10.1016/0092-8674(86)90620-3.

3. Ruskin B, Zamore PD, Green MR. A factor, U2AF, is required for U2 snRNP binding and splicing complex assembly. Cell. 1988;52(2):207-19. https://doi. org/10.1016/0092-8674(88)90509-0.

4. Raz N, Lindenberger U, Rodrigue KM, Kennedy KM, Head D, Williamson A, et al. Regional brain changes in aging healthy adults: general trends, individual differences and modifiers. Cerebral cortex (New York, NY : 1991). 2005;15(11):1676-89.

5. Mayne K, White JA, McMurran CE, Rivera FJ, de la Fuente AG. Aging and Neurodegenerative Disease: Is the Adaptive Immune System a Friend or Foe? Front Aging Neurosci. 2020;12(305):572090.

6. Cao W, Zheng H. Peripheral immune system in aging and Alzheimer's disease. Mol Neurodegener. 2018;13(1):51. https://doi.org/10.1186/s13024-01 8-0284-2.

7. Mazin P, Xiong J, Liu X, Yan Z, Zhang X, Li M, et al. Widespread splicing changes in human brain development and aging. Mol Syst Biol. 2013;9(1): 633. https://doi.org/10.1038/msb.2012.67.

8. Li H, Wang Z, Ma T, Wei G, Ni T. Alternative splicing in aging and agerelated diseases. Transl Med Aging. 2017;1:32-40. https://doi.org/10.1016/j. tma.2017.09.005

9. Chen J, Pan H-L. Dissecting molecular architecture of post-synaptic density at excitatory synapses: an editorial highlight for 'Hierarchical organization and genetically separable subfamilies of PSD95 postsynaptic supercomplexes' on page 504. J Neurochem. 2017;142(4):500-3. https://doi. org/10.1111/jnc.14084.

10. Zheng S, Gray EE, Chawla G, Porse BT, O'Dell TJ, Black DL. PSD-95 is posttranscriptionally repressed during early neural development by PTBP1 and PTBP2. Nat Neurosci. 2012;15(3):381-8, s381. https://doi.org/10.1038/nn.3026.

11. Angarola BL, Anczuków O. Splicing alterations in healthy aging and disease. WIRES RNA. 2021;12:e1643. 
12. Cole $S L$, Vassar R. The Alzheimer's disease $\beta$-secretase enzyme, BACE1. Mol Neurodegener. 2007;2(1):22. https://doi.org/10.1186/1750-1326-2-22.

13. Tanahashi $H$, Tabira T. Three novel alternatively spliced isoforms of the human beta-site amyloid precursor protein cleaving enzyme (BACE) and their effect on amyloid beta-peptide production. Neurosci Lett. 2001;307(1): 9-12. https://doi.org/10.1016/S0304-3940(01)01912-7.

14. Zohar O, Pick CG, Cavallaro S, Chapman J, Katzav A, Milman A, et al. Agedependent differential expression of BACE splice variants in brain regions of tg2576 mice. Neurobiol Aging. 2005;26(8):1167-75. https://doi.org/10.1016/j. neurobiolaging.2004.10.005.

15. Palop JJ, Mucke L. Amyloid-beta-induced neuronal dysfunction in Alzheimer's disease: from synapses toward neural networks. Nat Neurosci. 2010;13(7):812-8. https://doi.org/10.1038/nn.2583.

16. Guo T, Zhang D, Zeng Y, Huang TY, Xu H, Zhao Y. Molecular and cellular mechanisms underlying the pathogenesis of Alzheimer's disease. Mol Neurodegener. 2020;15(1):40. https://doi.org/10.1186/s13024-020-00391-7.

17. Tysoe C, Whittaker J, Xuereb J, Cairns NJ, Cruts M, Van Broeckhoven C, et al. A Presenilin-1 truncating mutation is present in two cases with autopsyconfirmed early-onset Alzheimer disease. Am J Hum Genet. 1998;62(1):70-6. https://doi.org/10.1086/301672.

18. Vetrivel KS, Zhang YW, Xu H, Thinakaran G. Pathological and physiological functions of presenilins. Mol Neurodegener. 2006;1(1):4. https://doi.org/10.11 86/1750-1326-1-4

19. Galganski L, Urbanek MO, Krzyzosiak WJ. Nuclear speckles: molecular organization, biological function and role in disease. Nucleic Acids Res. 2017;45(18):10350-68. https://doi.org/10.1093/nar/gkx759.

20. Lamond Al, Spector DL. Nuclear speckles: a model for nuclear organelles. Nat Rev Mol Cell Biol. 2003;4(8):605-12. https://doi.org/10.1038/nrm1172.

21. Sinclair GD, Brasch $K$. The reversible action of a-amanitin on nuclear structure and molecular composition. Exp Cell Res. 1978;111(1):1-14. https:// doi.org/10.1016/0014-4827(78)90230-6.

22. Saitoh N, Spahr CS, Patterson SD, Bubulya P, Neuwald AF, Spector DL. Proteomic analysis of Interchromatin granule clusters. Mol Biol Cell. 2004; 15(8):3876-90. https://doi.org/10.1091/mbc.e04-03-0253.

23. Mintz PJ, Patterson SD, Neuwald AF, Spahr CS, Spector DL. Purification and biochemical characterization of interchromatin granule clusters. EMBO J. 1999;18(15):4308-20. https://doi.org/10.1093/emboj/18.15.4308.

24. Younis I, Berg M, Kaida D, Dittmar K, Wang C, Dreyfuss G. Rapid-response splicing reporter screens identify differential regulators of constitutive and alternative splicing. Mol Cell Biol. 2010;30(7):1718-28. https://doi.org/10.112 8/MCB.01301-09.

25. Sanjana NE, Shalem O, Zhang F. Improved vectors and genome-wide libraries for CRISPR screening. Nat Methods. 2014;11(8):783-4. https://doi. org/10.1038/nmeth.3047.

26. Shalem O, Sanjana NE, Hartenian E, Shi X, Scott DA, Mikkelson T, et al. Genome-scale CRISPR-Cas9 knockout screening in human cells. Science. 2014;343(6166):84-7. https://doi.org/10.1126/science.1247005.

27. Zhao $Y$, Wu X, Li X, Jiang LL, Gui $X$, Liu Y, et al. TREM2 Is a Receptor for $\beta$ Amyloid that Mediates Microglial Function. Neuron. 2018;97(5):1023-31 e1027.

28. Gromova I, Celis JE. Chapter 27 - Protein Detection in Gels by Silver Staining: A Procedure Compatible with Mass Spectrometry. In: Celis JE, editor. Cell Biology. 3rd ed. Burlington: Academic Press; 2006. p. 219-23.

29. Zhou Y, Zhou B, Pache L, Chang M, Khodabakhshi AH, Tanaseichuk O, et al. Metascape provides a biologist-oriented resource for the analysis of systems-level datasets. Nat Commun. 2019;10(1):1523. https://doi.org/10.103 8/s41467-019-09234-6.

30. Szklarczyk D, Gable AL, Lyon D, Junge A, Wyder S, Huerta-Cepas J, et al. STRING v11: protein-protein association networks with increased coverage, supporting functional discovery in genome-wide experimental datasets. Nucleic Acids Res. 2019;47(D1):D607-d613. https://doi.org/10.1093/nar/ gky1131.

31. Shen S, Park JW, Lu ZX, Lin L, Henry MD, Wu YN, et al. rMATS: robust and flexible detection of differential alternative splicing from replicate RNA-Seq data. Proc Natl Acad Sci U S A. 2014;111(51):E5593-601. https://doi.org/10.1 073/pnas.1419161111.

32. Guo P, El-Gohary Y, Prasadan K, Shiota C, Xiao X, Wiersch J, et al. Rapid and simplified purification of recombinant adeno-associated virus. J Virol Methods. 2012;183(2):139-46. https://doi.org/10.1016/j.jviromet.2012.04.004.

33. Zhao Y, Tseng IC, Heyser CJ, Rockenstein E, Mante M, Adame A, et al. Appoptosin-mediated caspase cleavage of tau contributes to progressive
Supranuclear palsy pathogenesis. Neuron. 2015;87(5):963-75. https://doi. org/10.1016/j.neuron.2015.08.020.

34. Vorhees CV, Williams MT. Morris water maze: procedures for assessing spatial and related forms of learning and memory. Nat Protoc. 2006;1(2): 848-58. https://doi.org/10.1038/nprot.2006.116.

35. Jain S, Yoon SY, Zhu L, Brodbeck J, Dai J, Walker D, et al. Arf4 determines dentate gyrus-mediated pattern separation by regulating dendritic spine development. PLoS One. 2012;7(9):e46340. https://doi.org/10.1371/journal. pone.0046340.

36. Wang $X$, Zhao $Y$, Zhang $X$, Badie $H$, Zhou $Y, M u$ Y, et al. Loss of sorting nexin 27 contributes to excitatory synaptic dysfunction by modulating glutamate receptor recycling in Down's syndrome. Nat Med. 2013;19(4): 473-80. https://doi.org/10.1038/nm.3117.

37. Sithisarn P, Rojsanga P, Jarikasem S, Tanaka K, Matsumoto K. Ameliorative effects of Acanthopanax trifoliatus on cognitive and emotional deficits in olfactory Bulbectomized mice: an animal model of depression and cognitive deficits. Evid Based Complement Alternat Med. 2013;2013:701956.

38. Jung DH, Ahn SM, Pak ME, Lee HJ, Jung YJ, Kim KB, et al. Therapeutic effects of anodal transcranial direct current stimulation in a rat model of ADHD. Elife. 2020;9. https://doi.org/10.7554/eLife.56359.

39. Tsuda MC, Ogawa S. Long-lasting consequences of neonatal maternal separation on social behaviors in ovariectomized female mice. PLoS One. 2012;7(3):e33028. https://doi.org/10.1371/journal.pone.0033028.

40. Kamei D, Tsuchiya N, Yamazaki M, Meguro H, Yamada M. Two forms of expression and genomic structure of the human heterogeneous nuclear ribonucleoprotein D-like JKTBP gene (HNRPDL). Gene. 1999;228(1-2):13-22. https://doi.org/10.1016/S0378-1119(99)00020-7.

41. Akagi T, Kamei D, Tsuchiya N, Nishina Y, Horiguchi H, Matsui M, et al. Molecular characterization of a mouse heterogeneous nuclear ribonucleoprotein D-like protein JKTBP and its tissue-specific expression. Gene. 2000;245(2):267-73. https://doi.org/10.1016/S0378-1119(00)00032-9.

42. Spector DL, Lamond Al. Nuclear speckles. Cold Spring Harb Perspect Biol. 2011;3(2):a000646

43. Ximerakis M, Lipnick SL, Innes BT, Simmons SK, Adiconis X, Dionne D, et al. Single-cell transcriptomic profiling of the aging mouse brain. Nat Neurosci. 2019;22(10):1696-708. https://doi.org/10.1038/s41593-019-0491-3.

44. Ma N, Pan J, Ye X, Yu B, Zhang W, Wan J. Whole-transcriptome analysis of APP/PS1 mouse brain and identification of circRNA-miRNA-mRNA networks to investigate AD pathogenesis. Mol Ther Nucleic Acids. 2019;18:1049-62. https://doi.org/10.1016/j.omtn.2019.10.030.

45. Johnson ECB, Dammer EB, Duong DM, Ping L, Zhou M, Yin L, et al. Largescale proteomic analysis of Alzheimer's disease brain and cerebrospinal fluid reveals early changes in energy metabolism associated with microglia and astrocyte activation. Nat Med. 2020;26(5):769-80. https://doi.org/10.1038/s41 591-020-0815-6.

46. van der Feltz C, Hoskins AA. Structural and functional modularity of the U2 snRNP in pre-mRNA splicing. Crit Rev Biochem Mol Biol. 2019;54(5):443-65. https://doi.org/10.1080/10409238.2019.1691497.

47. Frendewey D, Keller W. Stepwise assembly of a pre-mRNA splicing complex requires U-snRNPs and specific intron sequences. Cell. 1985;42(1):355-67. https://doi.org/10.1016/S0092-8674(85)80131-8.

48. Geuens T, Bouhy D, Timmerman V. The hnRNP family: insights into their role in health and disease. Hum Genet. 2016;135(8):851-67. https://doi.org/10.1 007/s00439-016-1683-5.

49. Ribic A, Liu $X$, Crair MC, Biederer T. Structural organization and function of mouse photoreceptor ribbon synapses involve the immunoglobulin protein synaptic cell adhesion molecule 1. J Comp Neurol. 2014;522(4):900-20. https://doi.org/10.1002/cne.23452.

50. Wang X, Liao S, Nelson ER, Schmalzigaug R, Spurney RF, Guilak F, et al. The cytoskeletal regulatory scaffold protein GIT2 modulates mesenchymal stem cell differentiation and osteoblastogenesis. Biochem Biophys Res Commun. 2012;425(2):407-12. https://doi.org/10.1016/j. bbrc.2012.07.111.

51. Montesinos MS, Dong W, Goff K, Das B, Guerrero-Given D, Schmalzigaug R, et al. Presynaptic deletion of GIT proteins results in increased synaptic strength at a mammalian central synapse. Neuron. 2015;88(5):918-25. https://doi.org/10.1016/j.neuron.2015.10.042

52. Mohan V Wade SD, Sullivan CS, Kasten MR, Sweetman C, Stewart R, et al. Close homolog of $L 1$ regulates dendritic spine density in the mouse cerebral cortex through Semaphorin 3B. J Neurosci. 2019;39(32):6233-50. https://doi.org/10.1523/JNEUROSCI.2984-18.2019. 
53. Mori T, Kasem EA, Suzuki-Kouyama E, Cao X, Li X, Kurihara T, et al. Deficiency of calcium/calmodulin-dependent serine protein kinase disrupts the excitatory-inhibitory balance of synapses by down-regulating GluN2B. Mol Psychiatry. 2019;24(7):1079-92. https://doi.org/10.1038/s41380-018-033 8-4.

54. Ksiazek I, Burkhardt C, Lin S, Seddik R, Maj M, Bezakova G, et al. Synapse loss in cortex of Agrin-deficient mice after genetic Rescue of Perinatal Death. J Neurosci. 2007;27(27):7183-95. https://doi.org/10.1523/JNEUROSCl.1609-07.2 007.

55. Badea A, Schmalzigaug R, Kim W, Bonner P, Ahmed U, Johnson GA, et al. Microcephaly with altered cortical layering in GIT1 deficiency revealed by quantitative neuroimaging. Magn Reson Imaging. 2021;76:26-38. https://doi. org/10.1016/j.mri.2020.09.023

56. Alicea D, Perez M, Maldonado C, Dominicci-Cotto C, Marie B. Cortactin is a regulator of activity-dependent synaptic plasticity controlled by wingless. J Neurosci. 2017;37(8):2203-15. https://doi.org/10.1523/JNEUROSCI.1375-16.2 017.

57. El-Husseini AE-D, Schnell E, Chetkovich DM, Nicoll RA, Bredt DS. PSD-95 involvement in maturation of excitatory synapses. Science. 2000;290(5495): 1364-8.

58. Nazarko O, Kibrom A, Winkler J, Leon K, Stoveken H, Salzman G, et al. A Comprehensive Mutagenesis Screen of the Adhesion GPCR Latrophilin-1/ ADGRL1. iscience. 2018;3:264-78.

59. McIntire LB, Berman DE, Myaeng J, Staniszewski A, Arancio O, Di Paolo G, et al. Reduction of synaptojanin 1 ameliorates synaptic and behavioral impairments in a mouse model of Alzheimer's disease. J Neurosci. 2012. 32(44):15271-6. https://doi.org/10.1523/JNEUROSCI.2034-12.2012.

60. Hoy JL, Constable JR, Vicini S, Fu Z, Washbourne P. SynCAM1 recruits NMDA receptors via protein 4.1B. Mol Cell Neurosci. 2009;42(4):466-83. https://doi. org/10.1016/j.men.2009.09.010.

61. Duflocq A, Chareyre F, Giovannini M, Couraud F, Davenne M. Characterization of the axon initial segment (AIS) of motor neurons and identification of a para-AIS and a juxtapara-AIS, organized by protein 4.1B. BMC Biol. 2011;9(1):66. https://doi.org/10.1186/1741-7007-9-66.

62. Biundo F, Del Prete D, Zhang H, Arancio O, D'Adamio L. A role for tau in learning, memory and synaptic plasticity. Sci Rep. 2018;8(1):3184. https://doi. org/10.1038/s41598-018-21596-3.

63. Jaworski J, Kapitein LC, Gouveia SM, Dortland BR, Wulf PS, Grigoriev I, et al. Dynamic microtubules regulate dendritic spine morphology and synaptic plasticity. Neuron. 2009;61(1):85-100. https://doi.org/10.1016/j.neuron.2 008.11.013.

64. Liang Z, Zhan Y, Shen Y, Wong CCL, Yates JR, Plattner F, et al. The pseudokinase CaMKv is required for the activity-dependent maintenance of dendritic spines. Nat Commun. 2016;7(1):13282. https://doi.org/10.1038/ ncomms13282.

65. Cao W, Razanau A, Feng D, Lobo VG, Xie J. Control of alternative splicing by forskolin through hnRNP K during neuronal differentiation. Nucleic Acids Res. 2012;40(16):8059-71. https://doi.org/10.1093/nar/gks504.

66. Xue Y, Zhou Y, Wu T, Zhu T, Ji X, Kwon Y-S, et al. Genome-wide analysis of PTB-RNA interactions reveals a strategy used by the general splicing repressor to modulate exon inclusion or skipping. Mol Cell. 2009;36(6):9961006. https://doi.org/10.1016/j.molcel.2009.12.003.

67. Xiao R, Tang P, Yang B, Huang J, Zhou Y, Shao C, et al. Nuclear matrix factor hnRNP U/SAF-A exerts a global control of alternative splicing by regulating U2 snRNP maturation. Mol Cell. 2012;45(5):656-68. https://doi.org/10.1016/j. molcel.2012.01.009.

68. Li RZ, Hou J, Wei Y, Luo X, Ye Y, Zhang Y. hnRNPDL extensively regulates transcription and alternative splicing. Gene. 2019;687:125-34. https://doi. org/10.1016/j.gene.2018.11.026.

69. Xu J, Patassini S, Rustogi N, Riba-Garcia I, Hale BD, Phillips AM, et al. Regional protein expression in human Alzheimer's brain correlates with disease severity. Commun Biol. 2019;2(1):43. https://doi.org/10.1038/s42003018-0254-9.

70. Shi Q, Chowdhury S, Ma R, Le KX, Hong S, Caldarone BJ, et al. Complement C3 deficiency protects against neurodegeneration in aged plaque-rich APP/ PS1 mice. Sci Transl Med. 2017;9(392):eaaf6295.

\section{Publisher's Note}

Springer Nature remains neutral with regard to jurisdictional claims in published maps and institutional affiliations.

Ready to submit your research? Choose BMC and benefit from:

- fast, convenient online submission

- thorough peer review by experienced researchers in your field

- rapid publication on acceptance

- support for research data, including large and complex data types

- gold Open Access which fosters wider collaboration and increased citations

- maximum visibility for your research: over $100 \mathrm{M}$ website views per year

At $\mathrm{BMC}$, research is always in progress.

Learn more biomedcentral.com/submissions 